\title{
Protein Disulfide Isomerase Modulates the Activation of Thyroid Hormone Receptors
}

\author{
Jessica L. O. Campos ${ }^{1,2}$, Tabata R. Doratioto ${ }^{1,2}$, Natalia B. Videira ${ }^{1,2}$, \\ Helder V. Ribeiro Filho ${ }^{1,2}$, Fernanda A. H. Batista ${ }^{1}$, Juliana Fattori ${ }^{1}$, \\ Nathalia de C. Indolfo ${ }^{1,2}$, Marcel Nakahira ${ }^{3}$, Marcio C. Bajgelman ${ }^{1}$, Aleksandra Cvoro ${ }^{4}$, \\ Francisco R. M. Laurindo ${ }^{5}$, Paul Webb ${ }^{6}$ and Ana Carolina M. Figueira ${ }^{1 *}$ \\ ${ }^{1}$ Brazilian Biosciences National Laboratory (LNBio), Brazilian Center for Research Energy and Materials (CNPEM), São Paulo, \\ Brazil, ${ }^{2}$ Graduation Program of Biosciences and Bioactive Products Technology, Institute of Biology, State University of \\ Campinas (Unicamp), São Paulo, Brazil, ${ }^{3}$ Institute of Chemistry (IQ), State University of Campinas (Unicamp), São Paulo, \\ Brazil, ${ }^{4}$ Genomic Medicine, The Methodist Hospital Research Institute, Houston, TX, United States, ${ }^{5}$ Vascular Biology \\ Laboratory, Heart Institute (InCor), School of Medicine, University of São Paulo, São Paulo, Brazil, ${ }^{6}$ California Institute for \\ Regenerative Medicine, Oakland, CA, United States
}

Thyroid hormone receptors (TRs) are responsible for mediating thyroid hormone (T3 and T4) actions at a cellular level. They belong to the nuclear receptor (NR) superfamily and execute their main functions inside the cell nuclei as hormone-regulated transcription factors. These receptors also exhibit so-called "non-classic" actions, for which other cellular proteins, apart from coregulators inside nuclei, regulate their activity. Aiming to find alternative pathways of TR modulation, we searched for interacting proteins and found that PDIA1 interacts with TR $\beta$ in a yeast two-hybrid screening assay. The functional implications of PDIA1-TR interactions are still unclear; however, our coimmunoprecipitation (co-IP) and fluorescence assay results showed that PDI was able to bind both TR isoforms in vitro. Moreover, T3 appears to have no important role in these interactions in cellular assays, where PDIA1 was able to regulate transcription of TR $\alpha$ and TR $\beta$-mediated genes in different ways depending on the promoter region and on the TR isoform involved. Although PDIA1 appears to act as a coregulator, it binds to a TR surface that does not interfere with coactivator binding. However, the TR:PDIA1 complex affinity and activation are different depending on the TR isoform. Such differences may reflect the structural organization of the PDIA1:TR complex, as shown by models depicting an interaction interface with exposed cysteines from both proteins, suggesting that PDIA1 might modulate TR by its thiol reductase/isomerase activity.

Keywords: thyroid hormone receptor, protein disulfide isomerase, protein complexes, redox regulation, nuclear receptor signaling pathways

\section{INTRODUCTION}

Thyroid hormone receptors (TRs) are responsible for mediating thyroid hormone T3 and T4 (triiodothyronine and thyroxine, respectively) actions in cells $(1,2)$. Thyroid hormones (THs) are essential for normal development, neural differentiation, growth and metabolic regulation in mammals (3). Once secreted by the thyroid gland (mainly as T4), THs are carried in the plasma where they bind to proteins such as serum albumin, thyroxine-binding globulin and transthyretin, 
until they reach target tissues or cells, in which they are transported by specific carriers, resulting in the conversion of $\mathrm{T} 4$ into T3 $(4,5)$. In adults, the deficiency or excess of THs are usually associated with diseases, including hypo- and hyperthyroidism $(6,7)$.

TRs are encoded by two genes, THRA and THRB, located on chromosomes 17 and 3, respectively (8). Due to their alternative splicing, there are 4 major TR isoforms: TR $\alpha 1$ (410 aa.), TR $\alpha 2$ (492 aa.), $\operatorname{TR} \beta 1$ (461 aa.), and $\operatorname{TR} \beta 2$ (514 aa.) (4). The $\operatorname{TR} \beta$ subtypes only differ in the $\mathrm{N}$-terminal region, despite having the same actions (9-11). These isoforms diverge in expression patterns among tissues; $\mathrm{TR} \alpha 1$ and $\mathrm{TR} \alpha 2$ are predominantly expressed in the brain, heart, and skeletal muscle, while TR $\beta 1$ is considered ubiquitous, and $\mathrm{TR} \beta 2$ is expressed in the brain, inner ear and retina $(3,12)$.

These receptors belong to the nuclear receptor (NR) superfamily, acting inside the cell nuclei as hormone-regulated transcription factors (2). TRs have three distinct domains: an $\mathrm{N}$ terminal transactivation domain (NT), a central DNA binding domain (DBD), and a C-terminal ligand binding domain (LBD) $(13,14)$. This last domain displays a hydrophobic pocket that recognizes and binds to THs (15). Through the DBD, TRs bind to short DNA sequences, which are the thyroid hormone responsive elements (TREs) that are located in regulatory regions of target genes. Preferably, they act as heterodimers together with retinoid X receptors (RXR) (8) and in general, when bound to TREs, they adopt a conformational configuration that allows corepressor complex recruitment, thereby repressing target gene transcription. After ligand binding, TRs activate gene transcription through conformational changes that allow dissociation of corepressors and recruitment of coactivators (15, 16). Hence, TRs, together with all transcription machinery, are able to up- and downregulate target genes depending on the cell type and on the presence/absence of their cognate hormones (1). TRs also provide so-called "non-classic" actions in which other cellular proteins, apart from coregulators, can also regulate their activity. These TR-interacting proteins are functionally diverse, ranging from tumor suppressors and promoters, to cytoskeletal architecture modulators, transcription regulators and many others (12), and depending on each partner bound to TR, the cells may execute different actions.

In addition, several studies have shown the presence of TRs in the cytoplasm not just transiently but also when interacting

\footnotetext{
Abbreviations: TR, Thyroid Hormone Receptor; PDIA1 or P4HB, Protein Disulfide Isomerase A1 or Prolyl 4-Hydroxylase Subunit Beta; NR, Nuclear Receptor; Co-IP, Co-Immunoprecipitation; T3, Triiodothyronine; T4, Thyroxine; TH, Thyroid Hormones; NT, N-terminal Transactivation Domain; DBD, DNA Binding Domain; LBD, Ligand Binding Domain; TRE, Thyroid Hormone Responsive Elements; CTBP, Cytosolic T3-Binding Protein; NADPH, Nicotinamide adenine dinucleotide phosphate; ER, Estrogen Hormone Receptor; GH, Growth Hormone; Ref-1, Redox Factor-1; GFP, Green Fluorescent Protein; y2h, yeast two-hybrid; 3-AT, 3-amino-1,2,4-triazole; WB, Western Blot; SEC, Size Exclusion Chromatography; CV, Column Volume; SEC-GF, Analytical Gel Filtration; DLS, Dynamic Light Scattering; PdI, Polydispersity Index; FITC, fluorescein isothiocyanate; Kd, Affinity Constant; pRL, Renilla reniformis luciferase; qRT-PCR, quantitative Real Time PCR; SRC1, nuclear receptor coactivator 1; PDB, Protein Data Bank; PPI, Protein-Protein Interaction.
}

with different cytoplasmic proteins (17-20). Moreover, THrelated signaling cascades without the presence of TRs were also reported. For example, cytosolic 3,5,3'-triiodo-L-thyronine (T3)-binding proteins (CTBPs) can execute these "non-genomic actions" (12), such as the dimeric $76 \mathrm{kDa}$ rat liver cytosol protein (20), the $38 \mathrm{kDa}$ human kidney cytosol protein (21), the NADPHactivated liver cytosol protein (22), and the cytosolic pyruvate kinase monomers PKM1 and PKM2 (22, 23). Subsequently, reports identified a $55 \mathrm{kDa}$ protein displaying disulfide-isomerase activity (24) in addition to a high affinity for T3 and estrogen $(24,25)$. Several follow up reports characterized this protein as protein disulfide isomerase (PDIA1 or $\mathrm{P} 4 \mathrm{HB}$ ), the first folding catalyst discovered, as mainly responsible for mediating oxidative protein folding in the endoplasmic reticulum (2527). As a dithiol-disulfide oxidoreductase, PDIA1 reduces, oxidizes and isomerizes disulfide bonds, helping to maintain a healthy calcium-rich oxidative environment in the endoplasmic reticulum lumen $(26,28)$. Another important function for this enzyme is its chaperone activity, which has been well-studied both in vitro and in vivo $(29,30)$.

PDIA1 is the founding member of a family containing more than 20 members and it comprises four thioredoxin domains: $a-b-b$ '-a'. The "a" domains exhibit redox catalytic WCGHC motifs, or the so-called "redox cysteines," which are essential for PDIA1 function as an oxidoreductase. The thioredoxin fold structure found in both "b" domains present no redox cysteines but is enriched in hydrophobic residues involved in substrate recognition and binding. Connecting $\mathrm{b}^{\prime}$ and $\mathrm{a}^{\prime}$ domains, there is a 19-residue short interdomain region, named $x$-linker, while at the $\mathrm{C}$-terminus region there is a highly acidic extension, involved in calcium binding and a KDEL motif (endoplasmic reticulum retrieval motif) (28).

Among all pathophysiology involving PDIA1, it is important to mention its role in the following: (i) neurodegenerative and protein misfolding-associated diseases; (ii) cancers, involving events such as cell migration and metastasis; (iii) endoplasmic reticulum stress; (iv) cytosolic retrotranslocation of un/misfolded proteins for proteasome-mediated degradation; (v) autoimmune processes, such as rheumatic heart disease; and (vi) as a bisphenol-A-binding protein in rat brains [for more information see review $(28,31)]$.

Considering the binding of estrogen hormone to PDIA1, it was shown that PDIA1 colocalized with estrogen hormone receptor $\alpha(\mathrm{ER} \alpha)$ in MCF-7 cell nuclei, thereby altering $\mathrm{ER} \alpha$ conformation and enhancing the ER $\alpha$-ERE interaction. Consequently, PDIA1 was able to mediate changes in gene expression regulated by $\mathrm{ER} \alpha$ (32). In addition, the overexpression of PDIA1 in GH3 cells suppressed growth hormone (GH) mRNA expression and GH release, suggesting that PDIA1 modulates T3induced gene expression (33). Follow-up studies clarified that PDIA1 plays a role in this gene regulation mechanism, as it modulates the redox state of Ref-1 (redox factor-1), which is responsible for changing the TR redox state and controlling $\mathrm{GH}$ gene expression (34).

Here, we found PDIA1 as a new partner of TRs. Through a yeast two-hybrid screening assay, we found that PDIA1 interacted with TR $\beta$. Furthermore, we explored whether PDIA1 
was able to directly bind to TRs, whether this interaction is guided by a specific TR isoform, whether the presence of T3 was relevant for this association and, most importantly, whether the TR:PDIA1 complex might influence TR-dependent gene regulation. Interestingly, we found that, in addition to interacting with TRs, PDIA1 plays a functional role in their modulation, thus altering target gene expression through a mechanism that may involve PDIA1 thiol reductase/isomerase activity.

\section{MATERIALS AND METHODS}

\section{Plasmid Constructs}

\section{Yeast Two-Hybrid Assays}

Oligonucleotides were designed to amplify and sub-clone the cDNAs encoding the amino acid sequence of the full length human TR $\beta$ in the pBTM116 vector.

\section{Mammalian Cells Assays}

The coding sequence of full-length human Flag-TR $\alpha 1$ and human Flag-TR $\beta 1$ were subcloned into lentiviral vector LV-IG in $\mathrm{XbaI}+\mathrm{NheI}$ sites, constructed by LVV Facility (Viral Vectors Lab inside LNBio), which consists in bicistronic IRES-GFP vector to quickly identify cells expressing the protein of interest by fluorescence microscopy. A plasmid containing flag tagged eGFP gene (eGFP-flag) was used as control in immunoprecipitation experiments.

\section{Reporter Gene Luciferase Assays}

Constructions containing Response Elements for TR (DR-4, F2, AP-1) were cloned as transcription regulators of Firefly Luciferase gene. A plasmid containing Renilla Luciferase (pRL) was used as internal control of transfection for data normalization. Other plasmids used contain the human gene of PDIA1 full length (pcDNA3.1- PDIA1); TR $\alpha-1$ (pcDNA3.1$\mathrm{TR} \alpha 1)$, and $\mathrm{TR} \beta-1$ (pcDNA3.1-TR $\beta 1)$ full length.

\section{Protein Expression in E. coli BL21 (DE3)}

All genes were cloned in pET28a $(+)$ expression vector, hTR $\alpha$ full length, hTR $\beta \Delta \mathrm{AB}$ (amino acids 102-461), and hPDIA1 full length, kindly donated by Dr. Francisco Laurindo's Research Group.

\section{Single Point Mutants}

TR $\beta-C 294 A$ or TR $\beta-C 298 A$ mutated plasmids were constructed by site-directed mutagenesis, following the protocol established in the QuikChange II Site-Directed Mutagenesis kit (Agilent Technologies). Primers for mutagenesis experiments were designed using the QuickChange ${ }^{\mathbb{R}}$ Primer Design Program (Agilent Technologies).

\section{Yeast Two-Hybrid Screening (y2h)}

The Screening of TR $\beta$ against HeLa Library was performed in Saccharomyces cerevisiae strain L40 [trp-25, his3 $\Delta 200$, leu2-3, ade2, LYS2::(lexAop) 4-HIS3, URA3::(lexAop)8lac GAL4], which contains the heterologous genes HIS3 and lacZ, according to a previous published study (35). The $\mathrm{pBTMK-TR} \beta$ vector was used to express the full-length human TR $\beta$, and pBTM116Kempty vector was used as a control. The autonomous activation of HIS3 gene was tested by co-transformation of yeast cells with pBTMK-TR $\beta$ and pACT2-empty vector (control), grown in minimal medium plates (without tryptophan, leucine, histidine) containing $5 \mathrm{mM}$ 3-amino-1,2,4-triazole (3-AT). Also, we performed Beta-Galactosidase Test, in which colonies expressing Gal4 gene becomes blue, meaning that transcription factor was reconstituted by protein interaction. The $\mathrm{y} 2 \mathrm{~h}$ screenings were performed against HeLa cDNA library, cloned in pACT2 vector, expressing GAL4 activation domain (Matchmaker System, Clontech). After discovering the interaction partners, we performed co-transformation to confirm each interaction.

\section{Cell Culture}

293T (ATCC ${ }^{\circledR}$ CRL-3216 ${ }^{\mathrm{TM}}$ ) and Hep G2 (ATCC ${ }^{\circledR}$ HB$8065^{\mathrm{TM}}$ ) cells were grown in Dulbecco's modified Eagle's medium (DMEM) supplemented with $10 \%$ fetal bovine serum (FBS), $100 \mathrm{U} / \mathrm{mL}$ of penicillin, $0.1 \mathrm{~g} / \mathrm{L}$ of streptomycin and $4 \mathrm{mmol} / \mathrm{L}$ glutamine, under $95 \%$ air and $5 \% \mathrm{CO}_{2}$ at $37^{\circ} \mathrm{C}$.

\section{Co-immunoprecipitation TR-PDIA1}

To validate the TR-PDIA1 interaction, we performed coimmunoprecipitation (Co-IP) experiments in 293T cell line expressing flag-TRs. Cells were grown until $70 \%$ confluence and plated in $100 \mathrm{~mm}$ petri dishes. Next day, cells were transfected with Flag-TR $\alpha 1$ or Flag-TR $\beta 1$ or empty vector. Four hours later cells were treated with T3 or DMSO (negative control) for $36 \mathrm{~h}$. After treatment, cells were collected and lysed in RIPA buffer. The lysates were cleared by centrifugation $(9,000 \times \mathrm{g}, 20 \mathrm{~min}$, $4^{\circ} \mathrm{C}$ ) and incubated overnight with Mouse anti-FLAG (M2 affinity gel, Sigma) or mouse anti-PDIA1 (R\&D, \#MAB4236). The beads were gently washed by centrifugation 3 times in Trisbuffered saline (TBS) pH 7.5 and the complexes were eluted by boiling the samples before running the SDS-Page gel. In the flag-TRs immunoprecipitation, through western blot (WB), we searched for PDIA1, using anti-PDIA1 (mouse anti human PDIA1, R\&D \#MAB4236). Aiming to confirm the interaction, we also immunoprecipitated PDIA1 and searched for the transient transfected flag-tagged TRs through WB, using specific antibodies (rabbit anti-DYKDDDDK Tag-Cell Signaling \#2044; mouse anti-flag-Sigma Aldrich \#A8592; mouse anti-TR $\alpha-R \& D$, PP-H2804-00; mouse anti-TR $\beta-R \& D$, PP-H3825A-00). Bands were quantified through Image Studio ${ }^{\mathrm{TM}}$ Lite (Li-Cor).

\section{Expression and Purification of TRs}

hPDIA1 full length, hTR $\alpha$ full length and hTR $\beta \triangle A B$ (amino acids 102-461) were expressed using pET28a $(+)$ expression vector in BL21(DE3) Escherichia coli cells. Bacteria harboring the expression plasmid were grown in $\mathrm{LB}$ medium at $22^{\circ} \mathrm{C}$, and protein expression was induced with $0.5 \mathrm{mmolL}^{-1}$ IPTG (16 h). Cells were harvested by centrifugation $(4,000 \times \mathrm{g}, 15 \mathrm{~min}$, $\left.4^{\circ} \mathrm{C}\right)$. TR $\alpha$ and PDIA1 pellet were suspended in BUFFER A (20 $\mathrm{mmolL}^{-1}$ Phosphate Buffer $\mathrm{pH} 7.5,300 \mathrm{mmolL}^{-1} \mathrm{NaCl}, 5 \%$ glycerol), and TR $\beta \triangle \mathrm{AB}$ in BUFFER B $\left(20 \mathrm{mmolL}^{-1}\right.$ Hepes $\mathrm{pH}$ $8,300 \mathrm{mmolL}^{-1} \mathrm{NaCl}, 5 \%$ glycerol). In both buffers, $2 \mathrm{mmolL}^{-1}$ of $\beta$-mercaptoethanol, $100 \mathrm{mmolL}^{-1} \mathrm{PMSF}$ and lysozyme were added to the suspension. Cell extracts were sonicated and centrifuged $\left(30,000 \times \mathrm{g}, 60 \mathrm{~min}, 4^{\circ} \mathrm{C}\right)$ in Avanti J26xPT 
centrifuge (Beckman Coulter, rotor JA-25-50) for clarification. Proteins extracts were incubated with Talon resin (Clontech) $(1 \mathrm{~L}$ culture/ $1 \mathrm{~mL}$ resin) and were eluted with Buffers A or B with $300 \mathrm{mmolL}^{-1}$ imidazole and $2 \mathrm{mmolL}^{-1}$ of $\beta$-mercaptoethanol addition. Purity of samples was evaluated by SDS-PAGE. In addition, Size-Exclusion Chromatography (SEC) performed with Superdex 75 16/600 (GE Healthcare) column was used to improve purification of the proteins hTR $\alpha$ full length, $\operatorname{TR} \beta \Delta A B$, and hPDIA1 full length, obtained in affinity purification. The column was previously equilibrated with modified buffers A or B, with $150 \mathrm{mmolL}^{-1} \mathrm{NaCl}$ each. After that, proteins $(2 \mathrm{~mL}$, at $\sim 8 \mathrm{mg} / \mathrm{mL}$ ) were injected into the column and purification was performed at a flow rate of $0.3 \mathrm{~mL} / \mathrm{min}$. The isocratic elution was made with $1.5 \mathrm{CV}$. Fractions containing pure proteins were gathered and concentrated to be used in the next assays.

\section{Analytical Gel Filtration (GFSEC-GF)}

To analyze the radii from the proteins alone and in complex we utilized Superdex 200 HR 10/300 size exclusion column (1 $\times 30 \mathrm{~cm}$; GE Healthcare). The column was equilibrated with modified buffers A or B (150 $\mathrm{mmolL}^{-1} \mathrm{NaCl}, 2$ mM DTT added) at a flow rate of $0.5 \mathrm{~mL} / \mathrm{min}$ and standardized with the gel filtration calibration kits (GE Healthcare), applied in a volume of $100 \mu$ L. Ferritin, Aldolase, Conalbumin, Ovalbumin, Carbonic Anhydrase, Ribonuclease and Aprotinin with hydrodynamic radii of $6.1,4.8,3.6,3.0,2.0,1.6$, and $1.3 \mathrm{~nm}$, respectively, were used as calibration standards as recommended by manufacturers. The elution volumes of these proteins were used to calculate estimated hydrodynamic radii as described in \$(36). After calibration, following samples were injected and analyzed: $\mathrm{TR} \alpha$ and TR $\alpha$ :PDIA1 $(500 \mu \mathrm{L}$ at $\sim 0.75 \mathrm{mg} / \mathrm{mL})$; PDIA1 $(100 \mu \mathrm{L}$ at $\sim 2.5 \mathrm{mg} / \mathrm{mL})$; TR $\beta$ and TR $\beta$ :PDIA1 $(100 \mu \mathrm{L}$ at $\sim 2.5 \mathrm{mg} / \mathrm{mL})$. All curves profiles were analyzed in GraphPad Software.

\section{Dynamic Light Scattering (DLS)}

Pure proteins (hPDIA1 full, hTR $\alpha$ full, hTR $\beta \Delta \mathrm{AB}$ ), or in complex (TR $\alpha:$ PDIA1 and TR $\beta: P D I A 1$ ), at $\sim 1 \mathrm{mg} / \mathrm{mL}$, were analyzed in Dynamic light scattering (DLS) measurements. Those were conducted using the ZetaSizer NanoZS90 (Malvern) equipped with a 632.8-nm He-Ne laser and operating at an angle of $90^{\circ}$. For each sample, one measurement corresponds to $15-100$ acquisitions (according to sample concentration) of $10 \mathrm{~s}$, at $15^{\circ} \mathrm{C}$ with an automatic attenuator (Attenuation 11). The intensity size distribution, the $\mathrm{Z}$-average radius (Z-ave) and the polydispersity index (PdI) were obtained from the autocorrelation function using the "Protein Analysis mode" for the protein sample. The software used to collect and analyze the data was the ZetaSizer Software version 7.11 from Malvern.

\section{Fluorescence Anisotropy of TR:PDIA1 Complex}

The affinities of TR $\alpha$ full and TR $\beta$ DL for PDIA1 were measured by fluorescence anisotropy. TR $\alpha$ full and TR $\beta D L$ were previously labeled with fluorescein isothiocyanate (FITC) as previously described (37-39). Purified PDIA1 were titrated from 0.012 to $25 \mu \mathrm{mol} / \mathrm{L}$ into $50 \mathrm{nmol} / \mathrm{L} \mathrm{TR}(\alpha$ or $\beta)$-FITC solution, with and without triiodothyronine (T3), in assay buffer $(20 \mathrm{mM}$ Sodium
Phosphate $\mathrm{pH} 7.4,150 \mathrm{mM} \mathrm{NaCl}, 5 \mathrm{mM} \mathrm{MgCl}_{2}$ and $1 \mathrm{mM}$ DTT) in a 384-plate (Greiner, non-binding). For the experiments performed in the presence of $\mathrm{T} 3, \mathrm{TR} \alpha$, and $\operatorname{TR} \beta$ were previously incubated with 3 times molar excess of ligand, for $30 \mathrm{~min}$, at $5^{\circ} \mathrm{C}$. After mounting the plate series, specimens were left under incubation at $5^{\circ} \mathrm{C}$ for $20 \mathrm{~min}$ before the measurement. Fluorescence polarization was measured in CLARIOstar (BMG Labtech), Fluorescence Polarization-Endpoint was used as the detection mode, as well as, a $485 \mathrm{~nm}$ excitation filter, $565 \mathrm{~nm}$ longpass filter and a $540 \mathrm{~nm}$ emission filter, at $20^{\circ} \mathrm{C}$. Focus and Gain adjustments for both channels were set as recommended by manufacturers and all fluorescence experiments were performed at least in triplicate. Acquired data were analyzed using Mars Software and graphically edited in Origin software (version 8.0; OriginLab Corp), which applies the sigmoidal Hill1 model for fitting curves to determine the affinity constant $\left(\mathrm{K}_{\mathrm{d}}\right)$ and Hill coefficient values.

In addition, in order to evaluate if oxidized or reduced PDIA1 presented different affinities for TR $\alpha$ and $\operatorname{TR} \beta$, we first incubated PDIA1 with $0.5 \mathrm{mM} \mathrm{H}_{2} \mathrm{O}_{2}$ or with $0.5 \mathrm{mM}$ DTT, for $30 \mathrm{~min}$, to oxidize or reduced PDIA1 samples, respectively. Immediately after this incubation, PDIA1 were titrated from 0.012 to 25 $\mu \mathrm{mol} / \mathrm{L}$ into $50 \mathrm{nmol} / \mathrm{L} \mathrm{TR}(\alpha$ or $\beta)$-FITC solution, with and without triiodothyronine (T3), in assay buffer (20 mM Sodium Phosphate $\mathrm{pH} 7.4,150 \mathrm{mM} \mathrm{NaCl}, 5 \mathrm{mM} \mathrm{MgCl}_{2}$ ) in a 384plate (Greiner, non-binding) and Fluorescence polarization was measured as previously described. We also aimed to oxidize TRs to perform the same experiments, however oxidized TRs are not stable and forms aggregates (data evaluated by DLS, not shown) and, for this reason we just evaluated PDIA1 redox states in TR binding.

\section{Reporter Gene Assays}

293 T cells were trypsinized, resuspended in DMEM, plated in 24 -well plates (density of $1.1 \times 10^{5}$ cells/well), and incubated with the following plasmids: pBlueScript (used as empty DNA to equilibrate DNA quantity); pRL (which contains Renilla reniformis luciferase) used as the transfection control; F2-Luc (plasmid that contains positive response element for TR followed by firefly luciferase reporter gene); DR-4Luc (plasmid that contains positive response element for TR followed by firefly luc); AP-1Luc (plasmid that contains negative response element for TR followed by firefly luc); PDIA1 (plasmid with PDIA1 full gene); TR $\alpha$ (plasmid with TR $\alpha$ full gene); TR $\beta$ (plasmid with TR $\beta$ full gene); TR $\beta$-C294A (plasmid with TR $\beta$ C294A mutant full gene) or TR $\beta-C 298 \mathrm{~A}$ (plasmid with TR $\beta$ C298A mutant full gene). Plasmids were mixed with Lipofectamine ${ }^{\circledR} 2000$ (Invitrogen) in a ratio of $1.5 \mu \mathrm{g}$ of DNA to $2 \mu \mathrm{L}$ of Lipofectamine, at room temperature, for $20 \mathrm{~min}$ before addition to the cells. Hormone T3 (obtained from Sigma-Aldrich) was added at $1 \mu \mathrm{M}$ to the culture medium $4 \mathrm{~h}$ after the transfection. The cell monolayer was harvested $48 \mathrm{~h}$ later with lysis buffer (Dual Luciferase ${ }^{\mathrm{B}}$ Report Assay System; Promega) according to the manufacturer's instructions. Luciferase activity was determined using Dual Luciferase ${ }^{\circledR}$. Reporter Assay System (Promega) and measured in GloMax-Multi+ detection system (Promega). The $R$. reniformis luciferase activity was measured using the same 
cell lysate and used as an internal control. Transfection of the Response elements (DR4, F2, AP1) together with pBlueScript and treatments with T3 or DMSO were performed as a control of each reporter activation assay. In control all luciferase signals are due to endogenous activation of any endogenous NR. The activation values for TRs (wild type and mutants) and PDIA1 were obtained by normalization with this control. Statistical Analysis with One or Two-way ANOVA ${ }^{*} p<0.05,{ }^{* *} p<0.01,{ }^{* * *} p<0.001$.

\section{Knockdown PDIA1 Followed by qRT-PCR of T3 Target Genes}

SMARTpool ON-TARGETplusP4HB small interfering RNA (siRNA; number L-003690-00-0010) or non-targeting control (Dharmacon, GE Healthcare) was transfected into HepG2TR using Dharmafect cell culture reagent 4 (Dharmacon, GE

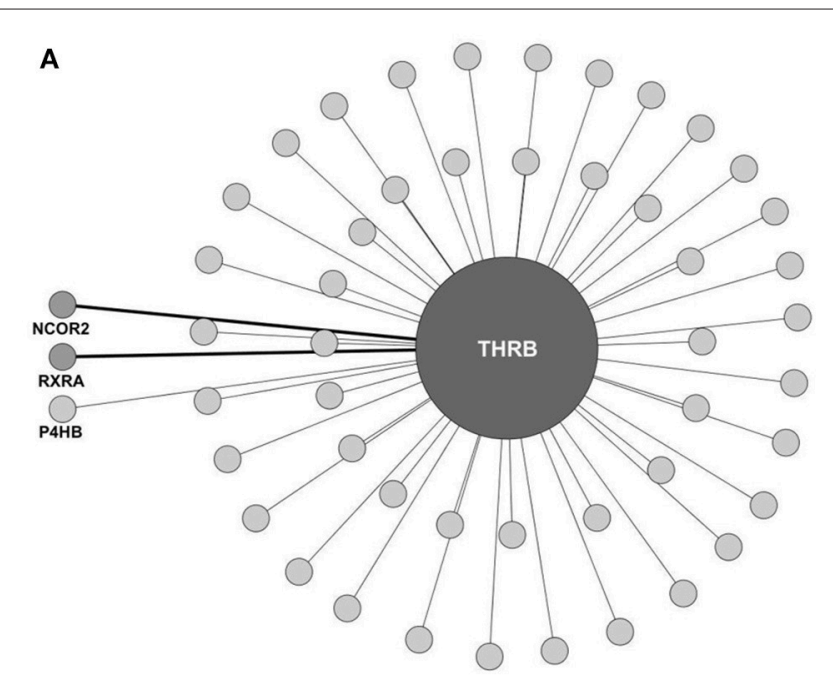

B

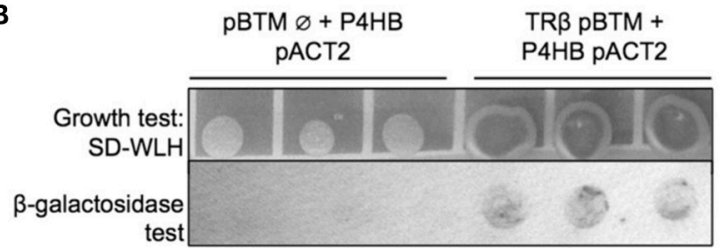

FIGURE 1 | TR $\beta$ yeast two-hybrid (y2h) screening. (A) Network created with IIS (Integrated Interactome System) platform and built in Cytoscape 3.3.0 software. $\mathrm{Y} 2 \mathrm{H}$ experiments identified 50 preys, among them, light-gray circles represent the new interactors found for TR $\beta$ (48 in total), and medium-gray, detached from circle, the already-known TR partners NCOR2 (Nuclear Receptor Corepressor 2) and RXRA (Retinoid X-Receptor $\alpha$ ). In light-gray, also detached from circle, we show the new TR $\beta$ partner found, Protein Disulfide Isomerase (PDIA1, also known as Prolyl 4-Hydroxylase Subunit Beta-P4HB). (B) Confirmation of PDIA1 and TR $\beta$ interaction found in Y2H assay. The TR $\beta$ and PDIA1 interaction reconstructed cell transcription factors machinery and transcribed genes that allows colonies to grow, we observe this in dark-grey colonies. Moreover, this interaction produced blue products in the $\beta$-galactosidase assay. Negative control with an empty vector (pBTM Ø) had no growth and in $\beta$-galactosidase assay, no blue color.
Healthcare) according to manufacturer's instructions. Following transfection, cells were cultured in medium for $48 \mathrm{~h}$ and then replicated into new plates. After $24 \mathrm{~h}$ of growth, cells were transfected again with siRNA, to increase the efficiency of the knockdown procedure; and $4 \mathrm{~h}$ later, T3/DMSO were added to media. Cells were collected $24 \mathrm{~h}$ later and all reactions were performed in triplicate.

We confirmed the knockdown through WB, so we compared the expression of PDIA1 (mouse anti human PDIA1, R\&D \#MAB4236) with the control beta-Actin (mouse anti-beta Actin-ABcam \#ab6276). Total RNA was extracted from cells using Qiazol Lysis Reagent (Invitrogen), and purified by RNeasy Mini kit (Qiagen) following manufacturer's instructions. Reverse transcription reactions were performed using $1 \mathrm{mg}$ of total RNA with an iScript cDNA Synthesis kit (Bio-Rad). Total RNA concentrations were measured using NanoDrop ND1000 spectrophotometer. Real-time qPCR was performed in Roche LightCycler 480 RT PCR Instrument using SYBR Green Mastermix (Roche). The sequences of the primers are listed in Supplementary Table 1. The data were collected and analyzed using the comparative threshold cycle method. Experiments were performed at least three times, and the standard error was calculated using the Prism curve-fitting program (GraphPad Software, version 3.03; GraphPad). Amplification curves were evaluated by the comparative $\mathrm{Ct}$ analyses.

\section{Fluorescence Anisotropy of Coactivator Peptide SRC1}

The affinities of the complex TR+T3:PDIA1 for coactivator peptide SRC1 were measured by titration assays using fluorescence anisotropy, as previously described (38). The labeled coregulator peptide SRC-1 (Fluorescein-SRC1-1 Coactivator Peptide 3 FITC-KYSQTSHKLVQLLTTTAEQQL) was obtained from Life-technologies. In control experiment, we titrated TR+T3 from 1 to $7,000 \mathrm{nM}$ in SRC1 at $50 \mathrm{nM}$. After that, we titrated the complex TR+T3:PDIA1 with the same concentrations gradient in SRC1. Protein complex stocks were diluted in the same buffer A or B. All fluorescence curves were fit as described $(37,38)$, using Origin software (version 8.0, Origin- Lab Corporation), which applies the LevenbergMarquardt algorithm for fitting curves to non-linear equations, to determine the Kd and Hill coefficient values. All fluorescence experiments were performed in triplicate.

\section{Molecular Docking}

Molecular docking experiments aimed to investigate structurally the interaction between PDIA1 and $\mathrm{TR} \alpha$ or TR $\beta$. Crystal structures of human TR $\alpha$ [PDB ID: $2 \mathrm{H} 77,(40)$ ] and TR $\beta$ [PDB ID: 3GWS, (40)] were obtained from Protein Data Bank (PDB, http://www.rcsb.org/pdb/). Full length human PDIA1 structure was modeled based on the oxidized form of yeast PDIA1 [PDB ID: 2B5E, (41)] and using the software YASARA (42). Docking experiments were performed, without any distance constraints, using the web server for protein-protein interaction prediction ClusPro (43). Additionally, the energy of the best predicted models was minimized using the software YASARA. 


\section{RESULTS}

\section{PDIA1 Is a New TR Partner}

Aiming to find new partners for TR, we first performed a yeast two-hybrid screen (y2h) using $\mathrm{TR} \beta$ as the bait (Figure 1A). The TR $\beta$ interactome map (Figure 1A) shows 48 new and 2 known protein partners. These 2 interactors for TR $\beta$ are NCor2 and $\operatorname{RXR} \alpha$, which have already been described as TR $\beta$ partners (detached from the circle in Figure 1A, medium-gray colored), which brings higher confidence to our data (3, 44-46). Among all 48 new potential interactors found with this assay (lightgray colored, Figure 1A), we found $\mathrm{P} 4 \mathrm{HB}$ (the gene coding for PDIA1). This protein was considered particularly important since it is also able to bind T3 hormone and to regulate a subset of TR genes (34). Subsequently, we decided to perform follow-up interaction confirmation assays ( $\beta$-Galactosidase and growth tests). These assays confirmed a TR $\beta$ :PDIA1 interaction (Figure 1B), as the cotransformation of yeast with both genes, TR $\beta$ and PDIA1, presented better growth in comparison with control cotransformants (empty vector and PDIA1 gene). Thus, a TR $\beta$ PDIA1 interaction was confirmed in yeast.

\section{PDIA1 Binds TR $\alpha$ and the TR $\beta$ Interactor in 293T Cells in the Absence or Presence of T3}

Once we found and confirmed the PDIA1 interaction in TR $\beta$ $\mathrm{y} 2 \mathrm{~h}$, we tested whether this interaction was modified by the presence/absence of ligands, or if it was selective for any TR isoforms (TR $\alpha$ and $\mathrm{TR} \beta$ ) in 293T cells. To do that, first, we confirmed the exogenous expression and activity of both TRs in 293T cells in reporter gene assays (Supplementary Figure 1). Band quantification showed some decrease in TR expression after T3 treatment, which was previously reported $(17,47)$

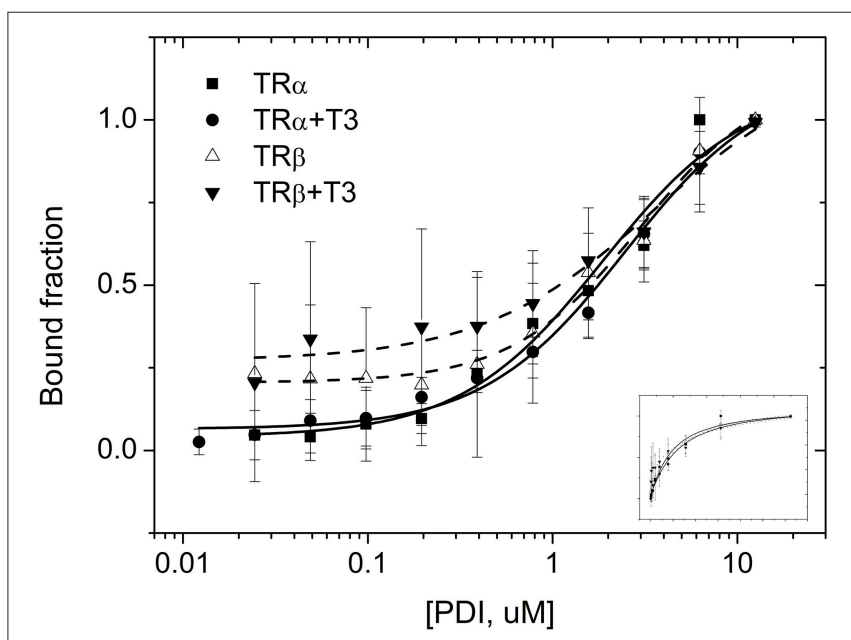

FIGURE 3 | Fluorescence anisotropy curves of TRs binding to PDIA1 in the presence or absence of T3. TR $\alpha$, as well as TR $\beta$, binds to PDIA1 with similar affinity, and T3 makes no difference in binding affinities (Kd). Insert, same fluorescence plot, without logarithm scale in the $x$-axis.
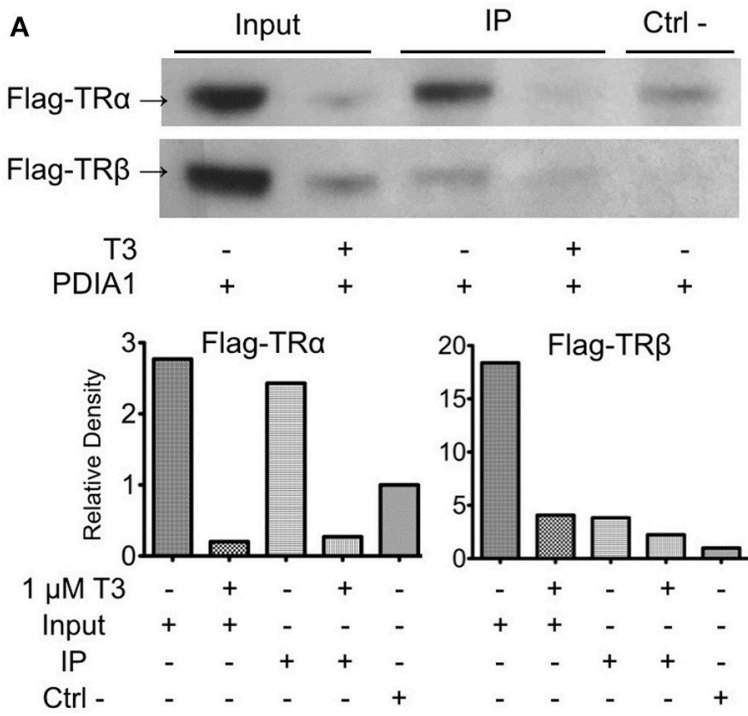

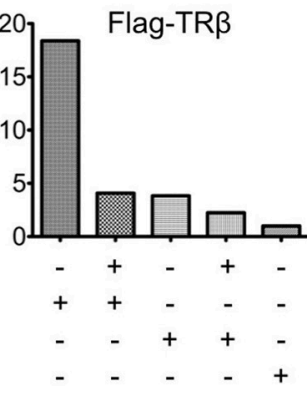

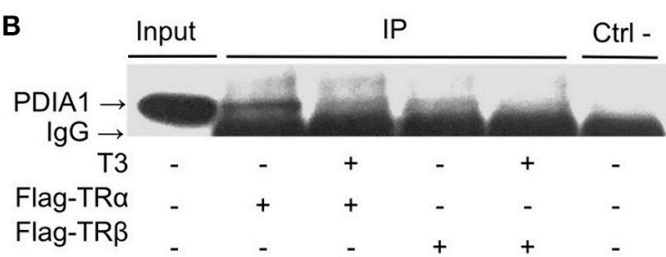

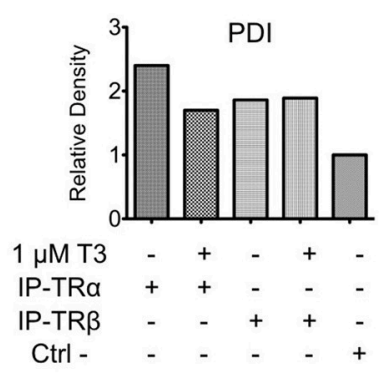

FIGURE 2 | Co-immunoprecipitation of TR:PDIA1 in 293T cells shows the interaction for both isoforms with or without T3 presence. (A) Immunoprecipitation of PDIA1 followed by Western Blot anti-flag, revealing Co-IP of PDIA1 and flag-TRs. The treatment with T3 (1 $\mu$ M) decreases TR expression in $293 \mathrm{~T}$ cell (input bands are thinner) reducing protein available to be immunoprecipitated. The interactions of TRs with PDIA1 were confirmed according to the quantification of bands (presented in the graphs below the WB). (B) Immunoprecipitation of flag tagged TRs (+ or -T3), and western blot anti-PDIA1. Control experiment WB anti-flag is presented in Supplementary Figure 2A, together with a confirmation experiment (Supplementary Figure 2B). Although WB shows strong lgG band, it is still possible to observe the presence of PDIA1 in all conditions, co-immunoprecipitated with both isoforms of TR. The quantification of bands are presented in graphs below WB, where all signals were normalized to the control signal (relative Density). 293T cell extracts without T3 and without transfection of flag-TRs were used on this experiment as negative control. Co-IP and WB experiments were performed more than once and here we show a representative image. 
and was not relevant for our assay. In addition, the flagTR reporter gene assay presented a considerable response to hormones (Supplementary Figure 1). After confirming these parameters, co-IP experiments for TRs and PDIA1 (Figure 2) showed that when PDIA1 was immunoprecipitated, more TRs were coimmunoprecipitated, mainly in the absence of ligands (Figure 2A), which was true for both TR isoforms, presenting additional evidence of a TR:PDIA1 interaction inside cells. Additionally, the inverse coimmunoprecipitation experiment was also performed, and the immunoprecipitated TRs were able to bring PDIA1, reinforcing the TR:PDIA1 interaction (Figure 2B). Although we observed IgG bands below PDI bands in the WB (Figure 2B), the quantification band software (illustrated in the graph below each co-IP western blot, Figure 2) helped us to analyze the presence or absence of antibody signals in each co-IP assay. Based on all the above tests, we confirmed one interesting, new protein partner for TR; moreover, we showed that this weak interaction, although visible through image analysis, is not responsive to T3 or selective to any TR isoform.

\section{Biophysical Characterization of TR:PDIA1 Complexes}

Biophysical assays were performed to confirm and characterize the direct interaction between TR:PDIA1 in vitro, aiming to gain more information about this complex formation and to address conditions in which this interaction happens.

First, SEC-GF experiments showed that TR:PDIA1 behaves as a complex, presenting an elution profile consistent with that of a bigger molecule than the isolated proteins. We also observed the presence of proteins alone and in complex through SDS-Page gels (data not shown) in each SEC and GF run, and bands from TR and PDI were observed in the complex lane. The calculated hydrodynamic radius of TR:PDIA1 complex in this assay was $4.0 \mathrm{~nm}$, which was higher than the calculated $R_{h}$ for $T R \alpha(2.8 \mathrm{~nm}), T R \beta$ $(2.9 \mathrm{~nm})$, and PDIA1 $(3.2 \mathrm{~nm})$ alone. These $\mathrm{R}_{\mathrm{h}}$ indicated that $\mathrm{TR} \alpha, \mathrm{TR} \beta$, and PDIA1 behave as monomers in solution and suggest that the TR:PDIA1 complex is formed by one TR and one PDIA1 monomer (Supplementary Figure 3, Supplementary Table 2).

Additionally, we subjected the TRs, PDIA1, and TRs:PDIA1 complexes to DLS experiments. The light scattering experiments revealed that TRs and PDIA1 behave as monomers, with a $\mathrm{R}_{\mathrm{h}}$ more similar to those described in the literature [PDIA1 $\mathrm{R}_{\mathrm{h}}=3.3 \mathrm{~nm}$ (48) and TRs $\mathrm{R}_{\mathrm{h}}$ monomer $=3.6 \mathrm{~nm}$ (36)], while TRs:PDIA1 complexes exhibited a $\mathrm{R}_{\mathrm{h}}=4.2 \mathrm{~nm}$. These differences in the absolute values may be intrinsic of technical approaches; however, in all cases, our results showed that TRs and PDIA1 behave as monomers in solution and their mixture behaves as larger units in SEC-GF and in DLS
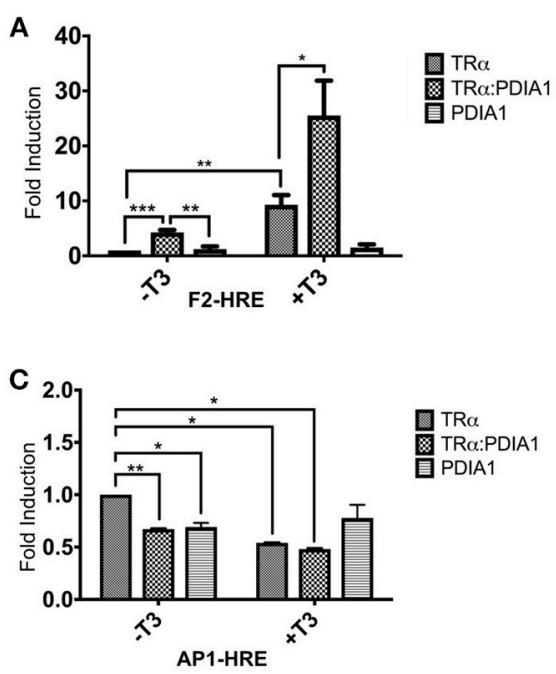

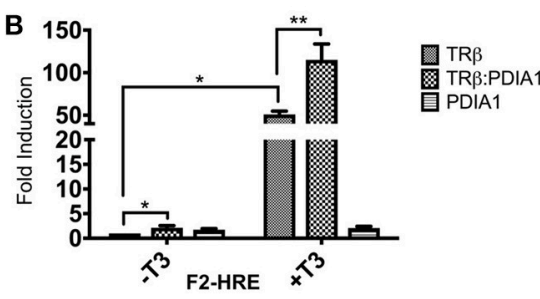

D

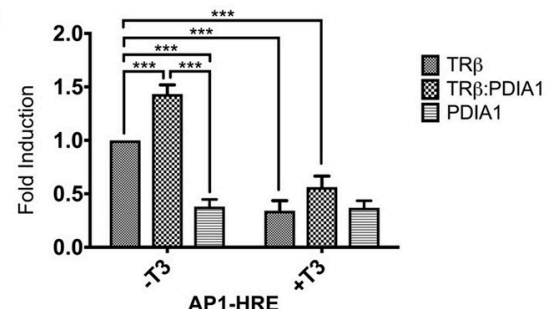

FIGURE 4 | Reporter gene luciferase assay shows PDIA1 acting on TRs gene regulation. Full length TR $\alpha$ or TR $\beta$, full length PDIA1 and Responsive Elements (REs) F2 and AP1, were transfected in 293T cells (in the presence and absence of T3), then luciferase activity was measured. All the TRs activation values were normalized by Renilla Luciferase activation. (A) In F2-Luc Response element, PDIA1 increased the basal activation of TR $\alpha$ in 4 times (*), and the T3 presence, which already increased TR $\alpha$ basal activation 9-fold $\left(^{\star *}\right)$, increased the TR $\alpha$ PDIA1 activation 3-fold higher (**), or 25 times the TR $\alpha$ basal activity. (B) PDIA1 presence, in F2-Luc Response element, increased basal activity of TR $\beta$ in 2-fold (*) independently of T3 presence, the T3 increased TR $\beta$ activity in 50 -fold (***), and PDIA1+T3 addition increased this activation in 2-fold $\left(^{\star \star \star}\right)$, which in total, reached 115 times the basal activity of TR $\beta$. (C) In AP1-Luc Response element, T3 repress basal activity of TR $\alpha$, PDIA1 presence was able to decrease the basal gene expression in both cases, with $\left(^{*}\right)$ and without T3 $\left(^{* \star}\right)$, and T3 and PDIA1 together were able to halving the

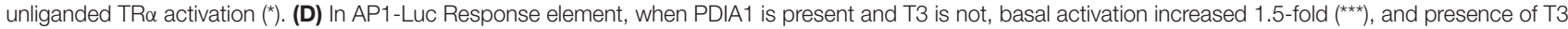
decreased even more this basal TR $\beta$ activation (about $60 \%$ ) $\left.{ }^{(* \star}\right)$. However, both PDIA1 and T3 together maintained the basal activation also repressed but in lower level (about 40\%) $\left(^{(\star \star}\right)$. In this last case, PDIA1 and T3 seemed to work in opposite directions. Statistical Analysis made with One-way or Two-way ANOVA ${ }^{\star} p<0.05$, ${ }^{* *} p<0.01,{ }^{\star * *} p<0.001$. 


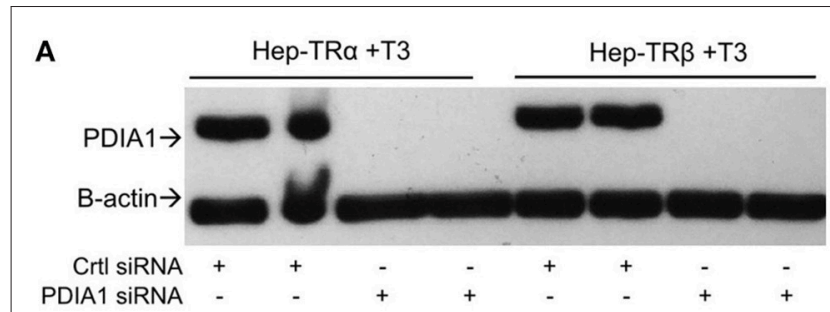

B

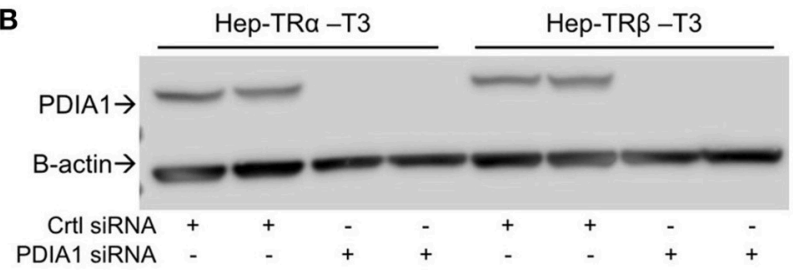

C
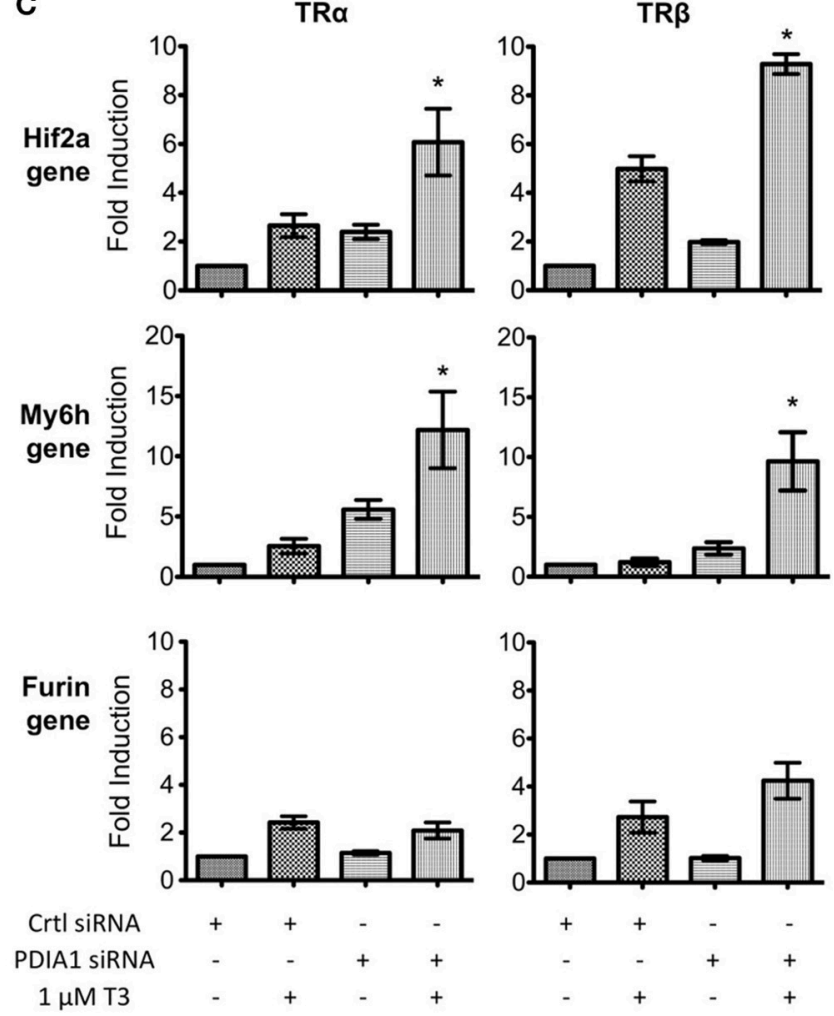

FIGURE 5 | Knockdown of PDIA1 in Hep-TR $\alpha$ and Hep-TR $\beta$ cell lines followed by qPCR. (A) Knockdown of PDI in Hep-TRs cell lines in T3 presence (+T3). Western blot shows the absence of PDIA1 protein in knockdown samples (PDIA1 siRNA). Cells were treated with $1 \mu \mathrm{M}$ of T3 for $6 \mathrm{~h}$ prior to cell harvesting. We presented here only 2 out of 3 knockdown experiments for each condition. Antibodies: anti-PDI and anti- $\beta$-Actin as loading control. (B) Knockdown of PDI in Hep-TRs cell lines in T3 absence (-T3). Western blot shows the absence of PDIA1 protein in knockdown samples (PDIA1 siRNA). Cells were treated with $1 \mu \mathrm{M}$ of DMSO for $6 \mathrm{~h}$ prior to cell harvesting. We presented here only 2 out of 3 knockdown experiments for each condition. Antibodies: anti-PDI and anti- $\beta$-Actin as loading control. (C) qPCRs for each cell line, Hep-TR $\alpha$ and Hep-TR $\beta$, with or without T3. Hif2a and Myh6 in absence of PDI (knockdown condition), increases transcription, Furin in absence of PDI (knockdown condition), did not alter gene expression. Each experiment was performed in three biological replicates. Statistical Analysis with One-way ANOVA * $p<0.05$. assays, which is a strong evidence of stable complex formation (Supplementary Table 2).

\section{The Binding of PDIA1 to TRs in vitro Is Also Independent of T3}

To access more information about complex formations, as well as isoform and ligand preferences, we performed fluorescence anisotropy assays to measure affinities between PDIA1 and TR $\alpha$ or TR $\beta$ in the presence or absence of T3. Our results showed that affinity constant $\left(\mathrm{K}_{\mathrm{d}}\right)$ values obtained from the binding curves (Figure 4) were $\sim 2 \mu \mathrm{M}$ for both TR isoforms in a reduced environment. When PDIA1 was titrated in TR $\alpha$, we obtained $\mathrm{K}_{\mathrm{d}}$ was $2.05 \pm 0.24 \mu \mathrm{M}$ in the absence of T3, and $1.97 \pm 0.18 \mu \mathrm{M}$ in the presence of T3. In addition, when PDIA1 was titrated in TR $\beta$, the $K_{d}$ were $2.71 \pm 0.27 \mu \mathrm{M}$ and $2.81 \pm 0.42 \mu \mathrm{M}$, respectively, without and with T3. Thus, we unambiguously confirmed that, in this assay condition, the presence of T3 was not able to induce any significant difference in the affinities between the TRs and PDIA1. Most importantly, these assays also showed that PDIA1 and TRs were able to interact with each other in vitro, displaying an affinity of $\sim 2.0 \mu \mathrm{M}$, without discrimination between TR isoforms.

\section{PDIA1 Changes the Transcriptional Activity of TRs in 293T Cells}

As TRs are nuclear receptors that regulate the expression of several genes and we were able to identify a direct interaction between PDIA1 and TRs, we investigated, in 293T cells, whether PDIA1 could interfere in the transcriptional activation of TRs. Using a reporter gene assay, we demonstrated, as expected $(49,50)$, an increase in transcriptional activity for both TRs in the presence of $\mathrm{T} 3$ at the $\mathrm{F} 2$ positive hormone response element (HRE) (Figures 4A,B). Moreover, we observed that in this HRE, when we added only PDIA1 to the system, the basal activation of TR $\alpha$ was increased 4-fold (Figure 4A). Additionally, in the presence of T3, which per se increased basal TR $\alpha$ activation 9-fold, the TR $\alpha$ :PDIA1 activation was increased by an additional 3-fold, for a 25-fold increase over the basal TR $\alpha$ activity (Figure 4A). In parallel, for TR $\beta$, in the F2-HRE system, PDIA1 incubation increased basal activity by 2 -fold (Figure 4B) independently of the presence of T3. We also observed that T3 increased TR $\beta$ activity by 50 -fold, and PDIA1 addition further increased this activation 2-fold, reaching a total of 115-fold of the basal TR $\beta$ activity (Figure 4B). In this way, in an activation context, PDI increased $\operatorname{TR} \alpha$ and $\operatorname{TR} \beta$ activation.

We also observed the previously reported (51) TR gene repression by $\mathrm{T} 3$ at the AP1 negative response element (52) (Figures 4C,D). Interestingly, our results showed that for the TR $\alpha$ assay (Figure 4C), PDIA1 incubation was able to decrease basal gene expression in both with and without T3. Additionally, T3 and PDIA1 together were able to reduce the basal TR $\alpha$ activation by $50 \%$. However, it is important to mention that, in the absence of $\mathrm{TR} \alpha$, PDIA1 showed basal repression of AP1, suggesting that PDIA1 action in AP1 promoter repression may be independent of $\operatorname{TR} \alpha$. 

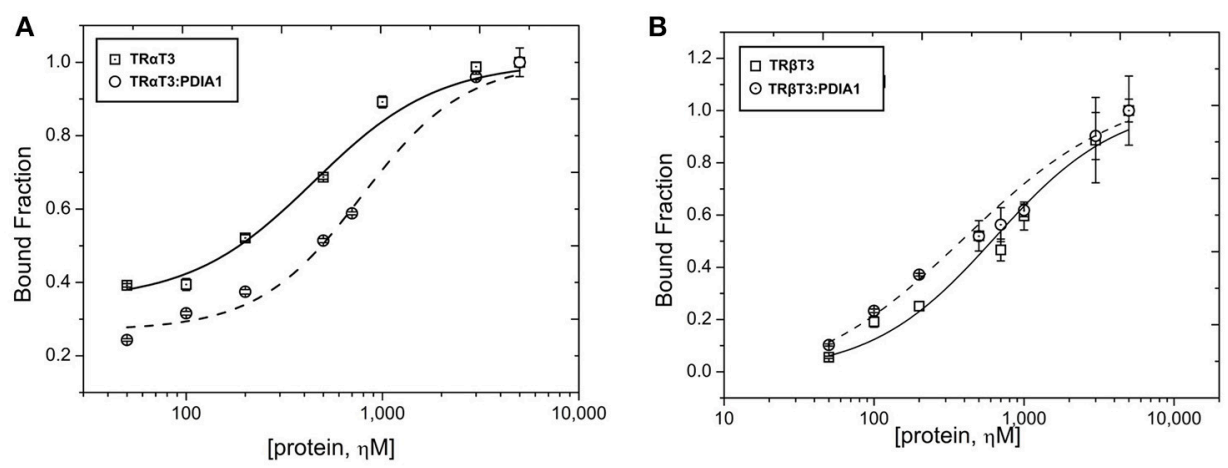

FIGURE 6 | Fluorescence anisotropy of liganded TRs or complex (TR+T3:PDIA1) on SRC1 coactivator. (A) Anisotropy curves of TR $\alpha+$ T3 with and without PDIA1 titration in $50 \mathrm{nM}$ of SRC1 peptide. (B) Anisotropy curves of TR $\beta+\mathrm{T} 3$ with and without PDIA1 titrated in $50 \mathrm{nM}$ of SRC1 peptide. These curves represent the average of the triplicate.

Surprisingly, for $\beta$ isoforms, in this same AP1-HRE (Figure 4D), we observed a different scenario. When PDIA1 was added to the system in the absence of T3, basal activation increased to 1.5-fold, while in the presence of T3, basal TR $\beta$ activation decreased $\sim 60 \%$. In addition, PDIA 1 and $\mathrm{T} 3$ together sustained the repression of basal activation, but at lower levels ( $\sim 40 \%)$. In the latter case, PDIA1 and T3 appeared to work in opposing directions depending on the TR isoform, and PDIA1 together with $\operatorname{TR} \beta$ appears to modify coregulator binding.

In summary, based on these experiments, we obtained two important findings. First, PDIA1 presence alone is sufficient to perturb TR gene regulation, depending on the promoter region observed. Specifically, our experiments showed that PDIA1 proportionally enhances TR activation in positive HREs, independently of the presence of T3. Second, we also showed that PDIA1 may regulate each TR isoform in a different and specific way concerning negative HREs, suggesting that it modulates TR $\beta$ repression in a stronger way than does the $\alpha$ isoform.

\section{PDIA1 Knockdown Affects TR-Regulated Gene Expression}

As PDIA1 was able to affect the transcriptional activity of both TRs, we performed PDIA1 knockdown to investigate whether PDIA1 effects sustain the expression of some welldescribed genes regulated by T3 (16). First, we observed that siRNA transfection in Hep-G2 cells expressing TR $\alpha$ or TR $\beta$ strongly reduced PDIA1 levels (Figures 5A,B and Supplementary Figure 4). Moreover, siRNA-mediated PDIA1 knockdown was confirmed at both mRNA and protein expression levels (Figures 5A,B, Supplementary Figure 4). Additionally, we further investigated the changes in Furin, Myh6 and Hif2a gene expression, known to be under strict T3 regulation (16) (Figure 5C).

Analysis of Hif2a gene expression (Figure 5C) showed increased gene transcription after PDIA1 knockdown for both TR isoforms, with a more evident increase in the presence of T3. Accordingly, Myh6 (Figure 5C) also behaved as a gene negatively regulated by PDIA1, given its increased expression
TABLE 1 | Measured dissociation constants (Kd, uM) of SRC1 binding to TR+T3 isoforms in the presence and absence of PDIA1.

\begin{tabular}{ccccccc}
\hline & \multicolumn{2}{c}{ SRC1 titrated in TR $\alpha+$ T3 } & & \multicolumn{2}{c}{ SRC1 titrated in TR $\beta+T 3$} \\
\cline { 2 - 3 } & -PDIA1 & +PDIA1 & & -PDIA1 & +PDIA1 \\
\hline $\mathrm{K}_{\mathrm{d}}, \mu \mathrm{M}$ & $0.29 \pm 0.04$ & $0.70 \pm 0.10$ & & $0.68 \pm 0.06$ & $0.39 \pm 0.06$ \\
\hline
\end{tabular}

after PDIA1 silencing. Interestingly, Furin gene expression (Figure 5C) showed no significant change after PDIA1 silencing, suggesting that PDIA1 is not essential for this specific gene regulation.

Given these results, we showed that PDIA1 may exert functional roles as a repressor of TR-regulated gene transcription, but apparently in a way restricted to specific genes, which should be investigated further.

\section{PDIA1 Changes the Recruitment of CoA by TR}

After characterizing the TR:PDIA1 interaction and showing that PDIA1 affects the activity of TR, we next investigated whether TR:PDIA1 complex formation alters the recruitment of TR coactivators. For that, we performed a fluorescence anisotropy assay to check the binding of TRs+T3:PDIA1 to the SRC1 peptide.

Prior to the study of the TR:PDIA1 complex, we addressed the binding of TRs to SRC1 as a control (Figures 6A,B). Given the $\mathrm{K}_{\mathrm{d}} \mathrm{s}$ found for SRC1:TR $\alpha+\mathrm{T} 3(0.29 \mu \mathrm{M})$ and SRC1:TR $\beta+\mathrm{T} 3$ $(0.68 \mu \mathrm{M})$, we assumed that both isoforms have a very high affinities for SRC1 peptides (Table 1). Following these $K_{d}$ determinations, we showed that PDIA1 incubation changes the affinities of $\operatorname{TR} \alpha$ or $\operatorname{TR} \beta$ in different ways. The affinity for coactivators was decreased with $\mathrm{TR} \alpha$ but increased with $\operatorname{TR} \beta$ ( TR $\alpha$ from $0.29 \pm 0.04 \mu \mathrm{M}$ to $0.7 \pm 0.1 \mu \mathrm{M}$, and $\mathrm{TR} \beta$ from $0.68 \pm$ $0.06 \mu \mathrm{M}$ to $0.39 \pm 0.06 \mu \mathrm{M}$, Table 1$)$. These results suggested that PDIA1 is not competing for coactivator recruitment because the complexes were able to bind to CoA peptide with $\mathrm{K}_{\mathrm{d}} \mathrm{s}$ in the same 
A

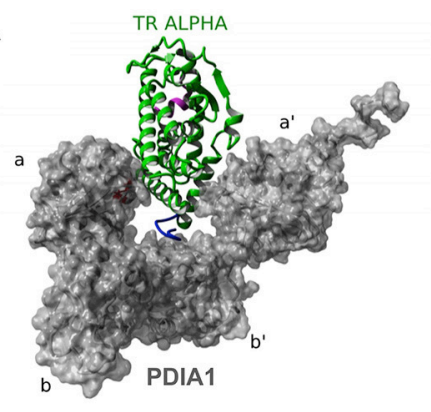

B

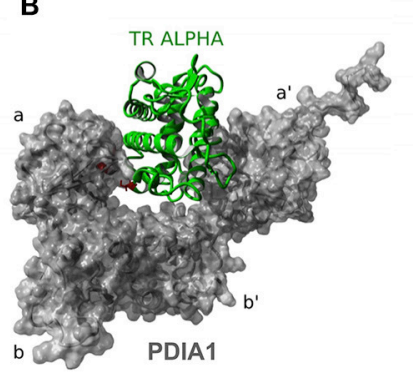

C

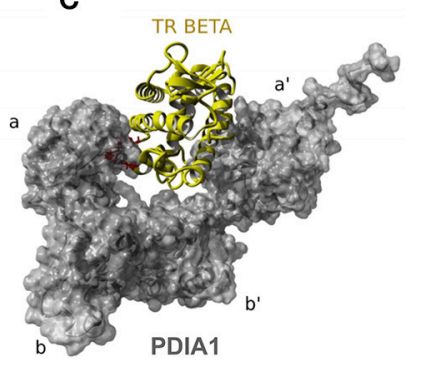

D

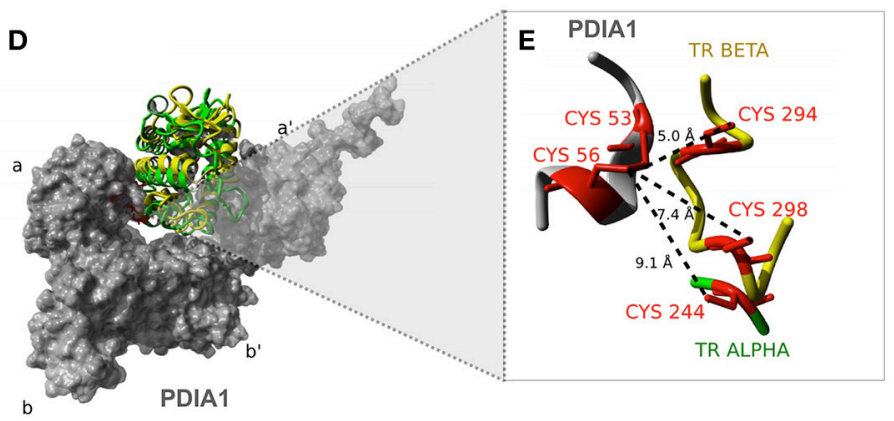

FIGURE 7 | Docking analysis of TR:PDIA1 binding sites. (A) Model I of TR $\alpha$ : PDIA1 interaction. Structural representation showing the interaction between TR $\alpha$ (green) and PDIA1 (surface presented in gray). The a, b, $\mathrm{a}^{\prime}$, and $\mathrm{b}^{\prime}$ Domains are shown in PDIA1 structure. In pink we show H12 helix. Hinge Domain of TR $\alpha$ is shown in blue. This domain interacts with domain $b^{\prime}$ of PDIA1. (B) Model II of TR $\alpha$ :PDIA1 interaction. Cysteines 53 and 56 of PDIA1 are close to cys244 in TR $\alpha$, located in H5. In pink we show H12 helix. (C) TR $\beta: P D I A 1$ interaction (similar to TR $\alpha: P D I A 1$ Model II). Structural representation showing the interaction between TR $\beta$ (yellow) and PDIA1 (surface presented in gray). In pink, the H12 helix. (D) Overlap of TR $\alpha$ and TR $\beta$ models (B,C). (E) Detail of PDIA1 cysteines and TR $\alpha$ and TR $\beta$ cysteines. Interaction between 53 and 56 cysteins of PDIA1 (red in gray) and 294 and 298 cysteins of TR $\beta$ (red in yellow) and 244 cysteine of TR $\alpha$ (red in green). Dotted lines show the distance between thiol groups of each protein.

order of magnitude as in the absence of PDIA1. Additionally, we propose that PDIA1 provokes conformational changes that might improve TR $\beta$ SRC1 binding and impair TR $\alpha$ SRC1 binding.

\section{Computational Modeling for the Hypothetical Surface of Interaction Between PDIA1 and TR}

Aiming to understand the structural mechanisms of interactions between PDIA1 and $\operatorname{TR} \alpha$ or $\operatorname{TR} \beta$, we performed molecular docking experiments. Using the web-based server ClusPro, we obtained a total of 111 clustered complexes for each TR isotype and selected the centers of the most populated clusters of low-energy structures as putative models (43).

The docking of the TR $\alpha$ PDIA1 complex resulted in two equally most likely conformational clusters. The central structure of the first cluster proposes that $\operatorname{TR} \alpha$ (green) interacts with PDIA1 (gray) fitting into the "boat" arrangement formed by the four domains of PDIA1 (Figure 7A, Model 1). One of them, the $b^{\prime}$ domain, accommodates one segment of the hinge region through a hydrophobic contact with the L154 residue of TR $\alpha$. Additionally, PDIA1 a and PDIA1 a' domains make direct contacts with helices $\mathrm{H} 10$ and $\mathrm{H} 11$, and $\mathrm{H} 1, \mathrm{H} 2$ and
H10 of $\mathrm{TR} \alpha$, respectively. The C-terminal helix H12, in turn, does not participate in the TR $\alpha$ :PDIA1 interface. In addition, an equally probably second model was suggested (model 2). This alternative also shows $\mathrm{TR} \alpha$ buried into the PDIA1 domains, but differently from the first model, and $\mathrm{TR} \alpha$ interacts in an alternative orientation (Figure 7B). In this model, the hinge does not contact PDIA1, but a more extensive interface is formed among TR $\alpha$, the PDIA1 a domain ( $\mathrm{H} 1, \mathrm{H} 3, \mathrm{H} 4, \mathrm{H} 5$, and H12), and the PDIA1 a' domain (H8, H10, and H11) was observed. Furthermore, residue E403 of H12 (TR $\alpha$ can make direct contact with the residue R97 from PDIA1 in this model.

Interestingly, docking of TR $\beta$ to PDIA1 resulted in one significantly more populated cluster, with $\operatorname{TR} \beta$ presented in the same orientation as that of $\mathrm{TR} \alpha$ model 2 (Figure 7C). In addition to the already described contacts for TR $\alpha$ model 2, this orientation of the TR $\beta$ :PDIA1 complex allows pairing of two cysteines from TR $\beta$ (C294 and C298) with the catalytic cysteines of PDIA1 (C53 and C56). As TR $\beta$ and TR $\alpha$ model 2 are in the same orientation in relation to PDIA1 (Figure 7D), it would be expected that a similar pairing of cysteines was also observed. However, only $\operatorname{TR} \beta$ has two cysteines to be paired, while $\operatorname{TR} \alpha$ has just one cysteine (C244) in the correspondent region. Moreover, $\mathrm{TR} \alpha \mathrm{C} 244$ is located further away from PDIA1 catalytic cysteines than TR $\beta$ C294 or C298 (Figure 7). 

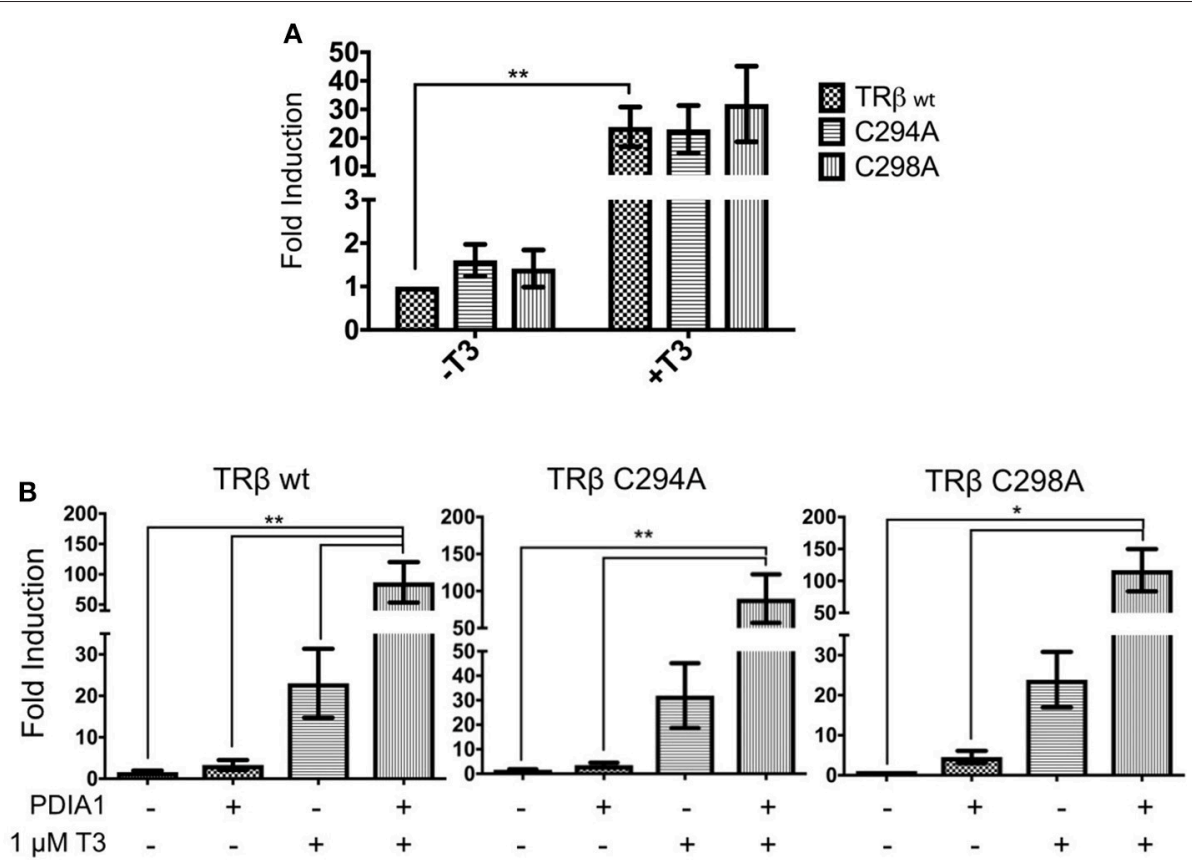

FIGURE 8 | Reporter gene luciferase assay shows PDIA1 acting on TR $\beta$ gene regulation. Full length TR $\beta$ wt, C294A, and C298A, full length PDIA1 and Responsive Element (RE) F2, were transfected in 293T cells (in the presence and absence of T3), then luciferase activity was measured. All the TRs activation values were normalized by Renilla Luciferase activation. (A) First, T3 hormone addition in all cases increased the transactivation, this shows that in terms of gene expression, both TR $\beta$ mutants were activated in a similar way. (B) PDIA1 presence in the TR $\beta$ mutant transactivation assay led to increase TR $\beta$-C294A and TR $\beta$-C298A basal activation by about 3- to 4-fold. On the other hand, in the presence of T3, PDIA1 promoted minor further reduction in TR $\beta$-C294A and TR $\beta$-C298A activation in comparison with wt TR $\beta$ (86-fold for C294A, 89-fold for C298A, and 115-fold for TR $\beta$ wt). Statistical Analysis with One-way or Two-way ANOVA ${ }^{*} p<0.05,{ }^{* *} p<0.01$.

\section{Site-Directed Mutagenesis of TRß-Cysteines}

According to the proximity between the catalytic cysteines of PDIA1 and the cysteines of TR presented in our docking model, we evaluated whether PDIA1 disulfide isomerase can affect TR activity by forming disulfide bonds at its paired cysteines. For this, we performed transactivation assays of mutated TR $\beta$ (TR $\beta$ C294A and TR $\beta$-C298A) in F2-response elements. Based on this, we expected that mutation of one cysteine from TR $\beta$ would lead to loss of its activity.

The mutations did not reduce overall activity of TR $\beta$, which maintained its transactivation function in the presence of T3 (Figure 8A). Surprisingly, incubation of PDIA1 in the TR $\beta$ mutant transactivation assay (Figure 8B) led to increased TR $\beta$ C294A and TR $\beta$-C298A basal activation by $\sim 3$ - to 4 -fold. On the other hand, in the presence of T3, PDIA1 promoted further minor reductions of TR $\beta-\mathrm{C} 294 \mathrm{~A}$ and TR $\beta-\mathrm{C} 298 \mathrm{~A}$ activation in comparison with wt TR $\beta$ (86-fold for C294A, 89-fold for C298A and 115 -fold for wt TR $\beta$ ). From this experiment, we concluded that the absence of one cysteine from TR $\beta$ was not capable of totally preventing PDIA1-mediated regulation of this receptor, but the decrease in TR+T3 activation was in line with $\mathrm{TR} \alpha$ wt behavior, which presented lower activation in comparison to TR $\beta$ wt. Thus, we suggest that the PDIA1 makes some influence in TR activation, more specifically over TR $\beta$ activation, which was made more significant by the presence of two cysteines (wt TR $\beta$ ) in comparison with just one cysteine (wt TR $\alpha$ or TR $\beta-C 294 \mathrm{~A}$ and $\operatorname{TR} \beta-\mathrm{C} 298 \mathrm{~A})$.

\section{Changes in the PDIA1 Redox State Modifies the Affinities for TR $\beta$}

To investigate whether the PDIA1 redox state might affect the binding of PDIA1 to TR, we determined its affinity for TR under a reducing (in presence of DTT) or oxidizing (in presence of $\mathrm{H}_{2} \mathrm{O}_{2}$ ) condition (Table 2, Figure 9). For TR $\alpha$, the PDIA1 redox state did not significantly change the affinity between both proteins $\left(\mathrm{Kd}_{\mathrm{TR} \alpha-\text { PDIA1Oxi }}=7.9 \pm 1.8 \mu \mathrm{M}\right.$ and $\mathrm{Kd}_{\mathrm{TR} \alpha \text {-PDIA1Red }}=10.7 \pm 1.3 \mu \mathrm{M}$ ), but the $\mathrm{Kd}$ sere slightly higher than the ones determined in the experiment done in the reduced environment (Kd $\sim 2 \mu \mathrm{M}$ ) (Table 2, Figure 9). This $\mathrm{Kd}$ difference may be explained by differences in experimental conditions since the first experiment used a reductive buffer, while the second was performed in conditions that did not favor reduction or oxidation, but the affinities are considered similar since they are in the same magnitude order. In other words, this experiment shows that oxidation or reduction of PDIA1 did not affect binding to TR $\alpha$. On the other hand, for TR $\beta$, PDIA1 oxidation disrupts $\mathrm{TR} \beta$ binding while PDIA1 reduction favors $\mathrm{TR} \beta$ association $\left(\mathrm{Kd}_{\mathrm{TR} \beta-\mathrm{PDIA1Oxi}}>>102 \pm\right.$ $264 \mu \mathrm{M}$ and $\mathrm{Kd}_{\mathrm{TR} \beta-\text { PDIA1Red }}=4.54 \pm 0.45 \mathrm{uM}$ ), indicating that the PDI redox state might be involved in TR $\beta$ recognition (Table 2, Figure 9). Moreover, our results suggested that a 
TABLE 2 | Measured dissociation constants ( $\mathrm{Kd}$, uM) of reduced and oxidized PDIA1 (PDI Red or PDI Oxi binding to TR isoforms.

\begin{tabular}{|c|c|c|c|c|}
\hline & \multicolumn{2}{|c|}{ PDIA1 titrated in TR $\alpha$} & \multicolumn{2}{|c|}{ PDIA1 titrated in TR $\beta$} \\
\hline & Oxi & Red & Oxi & Red \\
\hline $\mathrm{K}_{\mathrm{d}}, \mu \mathrm{M}$ & $7.9 \pm 1.8$ & $10.7 \pm 1.3$ & $>>102 \pm 264$ & $4.54 \pm 0.45$ \\
\hline
\end{tabular}

reduced environment favors PDIA1-TR association, which is more evident for a TR $\beta$ isoform that has two cysteines, probably interacting with PDIA1.

\section{DISCUSSION}

Considering the role of TRs in diseases such as resistance to thyroid hormone (RTH), thyroid cancers, dwarfism and general metabolic disorders (12), attributed to some of their non-classical actions, we aimed to screen other possible interactions that TRs might exhibit inside a cell. Taken together, our results lead us to conclude that: (i) PDIA1 is a new interaction partner for both TR isoforms and is able to bind these receptors at in vitro and cellular levels; (ii) T3 hormone plays a minor role in this interaction; (iii) PDI is able to regulate the transcription of selective genes through $\operatorname{TR} \alpha$ and $\operatorname{TR} \beta$ in different ways, depending on the isoform and promoter region involved; and (iv) although PDI did not directly act in coregulator recruitment, it improves binding of $\operatorname{TR} \beta$ to coactivators, and this binding appears to be under the modulation of disulfide bonds formed specifically in $\beta$ isoforms, but does not impair activity of TR $\alpha$.

Among the many different techniques that are used to discover new protein interactions, yeast two-hybrid screening (y2h) was chosen due to its robustness, simplicity, agility and capacity to identify binary interactions (53). We screened only the $\operatorname{TR} \beta$ isoform due to its facility to express in different cell types and standardization. The TR $\beta$ human gene was easily subcloned into the $\mathrm{y} 2 \mathrm{~h}$ assay vector $\mathrm{pBTM}$ and we found a large amount of new interactions for $\operatorname{TR} \beta$ and two already known ones. These four interactions confirmed the efficiency of the assay, while the almost 50 new interactions opened an unexpected range of new TR partners and mechanism of actions to be confirmed and further studied. Most importantly, this TR $\beta$ screening led us to the interaction with PDIA1 $(26,27,54)$.

Evidence from the NR and PDIA1 relationship came from two observations. One is that PDIA1 can bind hormones such as estradiol $(\mathrm{E} 2)$ and T3 $(16,25)$ due to the presence of two binding sites with comparable affinity for T3 $(4.3 \pm 1.4 \mu \mathrm{M})$; one of these overlaps with the estradiol binding site (25). In addition, it was reported that both hormones, E2 and T3, when bound to PDIA1, did not inhibit its chaperone or catalytic activity, making this protein a possible "reservoir" of hormones without lost activity $(25,55)$. The second is that PDIA1 has been proven to be not only an endoplasmic reticulum-related protein (56) but also is found in different cellular compartments, such as the nucleus $(32,57,58)$.

To confirm that PDIA1 could bind both TR isoforms with or without T3, we performed two different assays. First, we confirmed the TRs-PDIA1 interaction inside 293T cells through coimmunoprecipitation assays. Our results showed that PDIA1 coimmunoprecipitated with $\operatorname{TR} \alpha$ and $\operatorname{TR} \beta$ independent of the presence of T3. Therefore, this interaction was assured in two different cell systems: yeast and human embryonic cells (293T).

Before performing the second interaction assay, we expressed and purified PDIA1, TR $\alpha$ and TR $\beta$. Through the data obtained from DLS and SEC-GF (Supplementary Figure 3, Supplementary Table 2), we assumed that $\operatorname{TR} \alpha$ and $\operatorname{TR} \beta$ were eluted from SEC-GF as monomers with a $R_{h} \sim 3.0 \mathrm{~nm}$, as reported previously (36). Additionally, the complexes between each TR isoform and PDIA1 were formed and stabilized, according to data found in DLS and SEC-GF, which agreed with other TR complex formation data (39). Moreover, we performed a fluorescence anisotropy binding assay, and through this assay (Supplementary Figure 3), our results showed that PDIA1 could bind both TR isoforms, independently of the presence of $\mathrm{T} 3$ with reasonable affinity in a reduced environment. The measured $\mathrm{K}_{\mathrm{d}}$ was $\sim 2.0 \mu \mathrm{M}$ for both TR isoforms, which represents a relatively strong interaction, as previously found for the interaction between TR and GATA2-Zf (38). So far, it seems that hormones and isoforms played no important role in the in vitro TR:PDIA1 relationship. Although one of our hypotheses was that PDIA1 might bind to T3 and directly deliver it to TR, helping in its action, we observed in co-IP (Figure 2), affinity assays (Figure 3), and reporter gene (Figure 4) experiments that the hormone is not essential for TR:PDIA1 interactions, and we discarded this hypothesis.

In addition, we investigated whether TR:PDIA1 interactions might influence TR gene regulation, as reported for estrogen hormone receptor $\alpha(\mathrm{ER} \alpha)$ (32), by reporter gene assays (Figure 4). Our results primarily showed that PDIA1, in general, upregulated the transcription of the luciferase gene in all conditions through F2 HRE (Figures 4A,B). This may highlight a mechanism of action based on two different functions: chaperone-like or as coactivator-like, similarly to some other proteins, such as Dot1L (59), TET3 (60), and PGC-1 $\alpha$ (61).

Interestingly, we also observed very subtle differences in isoform modulation by PDIA1. One of these differences regards positive elements (F2, Figures 4A,B), in which PDIA1 increased basal activation of $\mathrm{TR} \alpha$, which was 2-fold stronger than basal activation of TR $\beta$. Additional evidence for the differential modulation of isoforms was observed in negative elements (AP1, Figures 4C,D), in which the presence of PDIA1 provoked antagonistic effects between $\operatorname{TR} \alpha$ and $\operatorname{TR} \beta$, decreasing the former by near $30 \%$ and increasing the later by $50 \%$. These results suggested that PDIA1 should play differential roles in isoform basal activation, probably interfering a corepressor dissociation and coactivator recruitment. More specifically, all data collectively suggest that corepressor dissociation might affect more $\mathrm{TR} \alpha$ isoforms, and coactivator recruitment may be facilitated for TR $\beta$ in the presence of PDIA1.

On the other hand, it is important to mention that the role of nuclear receptors in negative response elements (nHRE) is still not entirely clarified. Taking the already studied GATA2TR interaction as an example, it has been shown that T3 is able to weaken TR-nHRE interactions, which results in 

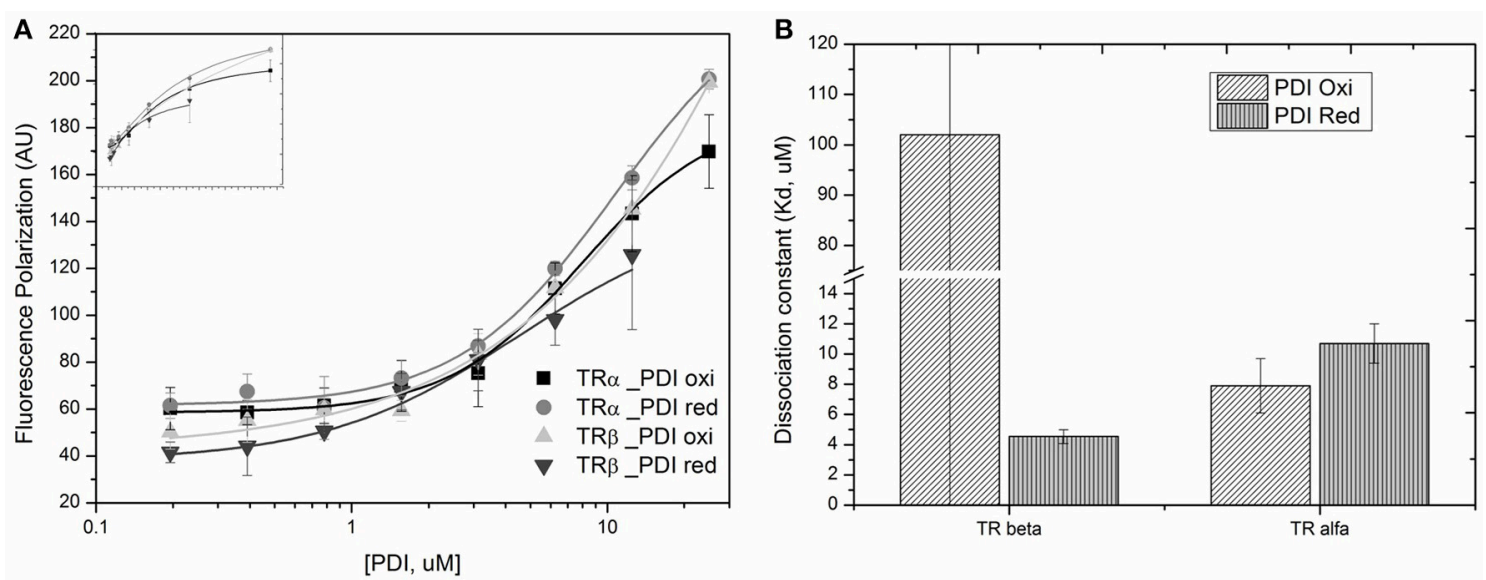

FIGURE 9 | Binding profile for TRs binding to PDIA1 under different redox state. (A) Anisotropy curves of PDIA1 titrated under TR $\alpha$ and TR $\beta$ labeled with FITC. (B) Binding constants found for TR $\alpha$ and TR $\beta$ bound to reduced or oxidized PDIA1 (PDI red or PDI red).

gene downregulation (36). However, in AP1 nHRE, T3 acted in both isoforms by downregulating luciferase expression, as expected. Interestingly PDIA1 presence per se was capable of downregulating the reporter gene only for $\mathrm{TR} \alpha$. Therefore, following this line, PDIA1 seems to have some comparable effects to those of GATA2-TR+T3 for this isoform and might be dissociating $\mathrm{TR} \alpha$ from its nHRE. However, if PDIA1 is truly interfering in coregulator binding, this could be a better explanation of why PDIA1 derepressed TR $\beta$ gene regulation in the AP1 site. In fact, NR coregulators were recently described as playing different roles depending on each transcription factor or promoter region that they regulate by either enhancing or blocking the transcription (51). This mechanism is also known as the reversal role of coregulators, which could be an explanation for why PDIA1 acts by increasing or derepressing gene expression in this particular case.

Regarding gene regulation, we performed knockdown of PDIA1 in HepG2-TR cell lines (Figure 5). Two of the selected genes, Hif2a and Myh6, presented the same expression profile in which PDIA1 repressed their expression. This is additional evidence that PDIA1 might interfere in coregulator recruitment for both genes but represses transcription. Again, here we observed that repression effects seem to be more pronounced in $\mathrm{TR} \alpha$ isoforms. In addition, PDIA1 absence had no relevance for the furin gene, which has no significant increase or decrease in its expression, revealing that its regulation might be promoter specific. So far, these results suggest two more perceptions on PDIA1 intervention in TR gene regulation. First, that PDIA1 action might be selective for each gene regulated by TR and, second, that the variety of regulating regions present in each gene promoter might be another factor that contributes to PDIA1 action.

To determine whether PDIA1 might act in TR-coregulator recruitment, by modification of their binding mode, or in their binding interfaces, we performed coactivator recruitment assays (Figure 7). Our results showed that PDIA1 presence did not affect overall coactivator binding, since the $\mathrm{K}_{\mathrm{d}} \mathrm{s}$ are in the same order of magnitude in the presence or absence of PDIA1. However, in a deep analysis, we observed that PDIA1 decreased affinity for TR $\alpha$ :SRC1 complex formation to $50 \%$ and improved the binding of TR $\beta: S R C 1$ in the same proportion. This reinforced the hypothesis that PDIA1 has some influence on TR isoform activation, more specifically regarding roles in coactivator recruitment.

In sequence, we built a computational model to observe possible interaction interfaces that are most energetically favorable in the complex formed between TR and PDIA1. Based on docking analysis of TR $\alpha$ and $\beta$ and PDIA1, we hypothesized about regions that were involved in the complex formation and about isoform differences in complex formation. As expected, a disulfide isomerase enzyme works through its active cysteines, but the proximity of those cysteines might result in reducing, oxidizing, and isomerizing disulfide bonds. In this way, we investigated whether PDIA1 might have some of these effects. Based on the three generated models, we observed the first dramatic difference between both isoforms: while TR $\alpha$ presented two possible binding modes to PDIA1, TR $\beta$ showed only one possibility for docking. Moreover, this unique binding mode for $\operatorname{TR} \beta$ was the same as "TR $\alpha$ model 2," indicating that this conformation is equally possible in both isoforms but is more stable for the $\beta$ isoform. This higher stabilization provided for the TR $\beta$ :PDIA1 complex may be a consequence of the presence of two cysteine residues next to each other, which are present in TR $\beta$ (Cys 298 and Cys 294) but not in TR $\alpha$. In addition, these two TR $\beta$ residues are close enough to PDIA1 cysteines (Cys 53 and Cys 56), as it was shown in our model in Figure 7, which may possibly provide the correct formation for $\mathrm{TR} \beta$ disulfide bonds. In more detail, these cysteines are located in the $\mathrm{H} 4-\mathrm{H} 5$ position, and it is notable to assume that a disulfide bond in this region might lead to a better interaction with coregulators, such as SRC1. In this way, it seems that PDIA1 may present redox isomerase activity for $\operatorname{TR} \beta$, as it was reported for Ref-1 $(62,63)$ and $\mathrm{GH}(34)$.

To investigate the possible roles of TR $\beta$ cysteines in TRPDIA1 interactions, we tested whether PDIA1 cysteines were 
important for TR $\beta$ transcriptional activity. So far, we made single-point mutations in TR $\beta$ (C298A and C294A), and the C294A mutant was more similar to $\mathrm{TR} \alpha$ in terms of sequence and cysteine residues. Nonetheless, our reporter gene assay (Figure 8) indicated that the mutations did not significantly change $\operatorname{TR} \beta$ activation by T3. The PDIA1 presence still increased TR $\beta$ activation, but to a lower degree. In other words, only one cysteine was enough to provide increased gene transcription under PDIA1 modulation, as it happened in $\operatorname{TR} \alpha$ and in TR $\beta$ mutants (C298A and C294A). However, the presence of two cysteines appears to better stabilize the receptor, thereby increasing gene transcription, which may reflect the oxidoreductase/isomerase activity of PDIA1 in this complex. Finally, we also observed that the change in the redox state of PDIA1 modifies its affinities for TR $\beta$ binding but not for TR $\alpha$ binding. These results confirmed the preference for TR $\beta$ binding to PDIA1 and suggested that the PDIA1 redox state is important for interactions with this receptor isoform. Moreover, our results indicated that a reduced environment favors the PDIA $1-\mathrm{TR} \beta$ interaction, suggesting that redox mechanisms might be involved in these protein interactions. Altogether, these results indicated that PDI regulates TRs through a different mechanism, which may involve disulfide bond formation in $\beta$ isoforms of this NR and might be related to a redox state of TR and PDIA1.

In summary, here we present PDIA1 as a new interaction partner for both TR isoforms, which are able to bind these receptors at different levels. In addition, T3 did not modify this interaction; while PDI is able to regulate the transcription of $\operatorname{TR} \alpha$ and $\operatorname{TR} \beta$ selective genes, depending on the isoform and promoter region involved. Moreover, despite PDI did not directly act in coregulator recruitment, our results indicate that it improves $\operatorname{TR} \beta$ binding to coactivators, and that this binding is under the modulation of disulfide bonds formed specifically in $\beta$ isoforms, but does not impair activity of $\mathrm{TR} \alpha$.

\section{REFERENCES}

1. Sachs LM. Unliganded Thyroid hormone receptor function: amphibian metamorphosis got TALENs. Endocrinology (2015) 156:409-10. doi: 10.1210/en.2014-2016

2. Schroeder A, Jimenez R, Young B, Privalsky ML. The ability of thyroid hormone receptors to sense $\mathrm{t} 4$ as an agonist depends on receptor isoform and on cellular cofactors. Mol Endocrinol. (2014) 28:745-57. doi: 10.1210/me.2013-1335

3. Brent GA. Mechanisms of thyroid hormone action. J Clin Investig. (2012) 122:3035-43. doi: 10.1172/JCI60047

4. Chan IH, Privalsky ML. Isoform-specific transcriptional activity of overlapping target genes that respond to thyroid hormone receptors alphal and beta1. Mol Endocrinol. (2009) 23:1758-75. doi: 10.1210/me.2009-0025

5. Flamant F, Baxter JD, Forrest D, Refetoff S, Samuels H, Scanlan TS, et al. International union of pharmacology. LIX The pharmacology and classification of the nuclear receptor superfamily: thyroid hormone receptors. Pharmacol Rev. (2006) 58:705-11. doi: 10.1124/pr.58.4.3

6. Moeller LC, Cao X, Dumitrescu AM, Seo H, Refetoff S. Thyroid hormone mediated changes in gene expression can be initiated by cytosolic action of the thyroid hormone receptor beta through the phosphatidylinositol 3-kinase pathway. Nuclear Receptor Signal. (2006) 4:e020. doi: 10.1621/nrs.04020

\section{AUTHOR CONTRIBUTIONS}

AF: conception and design of the study. JC, NV, HR, FB, JF, NI, and $\mathrm{MN}$ : experiments and data collection. JC, AF, NV, TD, NI, HR, AC, MB, and PW: data analysis. JC, AF, NV, NI, HR, PW, and FL: drafting and critical revision of the paper. JC, AF, PW, and FL: final revision to be published.

\section{FUNDING}

This work was supported by the Fundação de Amparo à Pesquisa do Estado de São Paulo (FAPESP; grant numbers \#2011/23659-2, \#2013/08743-2, \#2014/22215-1, \#2016/22246-0 and \#2013/07937-8; and Coordenação de Aperfeiçoamento de Pessoal de Nível Superior (CAPES; grant number 23038.006737/2012-56).

\section{ACKNOWLEDGMENTS}

We thank LNBio/CNPEM for accessibility to Protein Purification Laboratory (LPP), the Spectroscopy and Calorimetry (LEC), Bioassays (LBE) and Bioinformatics (LBI) facilities. Also, we are very grateful to Fundação de Amparo à Pesquisa do Estado de São Paulo (FAPESP; grant numbers \#2011/23659-2, \#2013/087432, \#2014/22215-1, \#2016/22246-0 and \#2013/07937-8; and Coordenação de Aperfeiçoamento de Pessoal de Nível Superior (CAPES; grant number 23038.006737/2012-56). Finally, we would like to thank Luis Felipe Ferreira Vidal, Aline Bridi, and Michele A. Assis for technical support.

\section{SUPPLEMENTARY MATERIAL}

The Supplementary Material for this article can be found online at: https://www.frontiersin.org/articles/10.3389/fendo. 2018.00784/full\#supplementary-material

7. Onigata K, Szinnai G. Resistance to thyroid hormone. Endocrine Development (2014) 26:118-29. doi: 10.1159/000363159

8. Pascual A, Aranda A. Thyroid hormone receptors, cell growth and differentiation. Biochim Biophys Acta (2013) 1830:3908-16. doi: 10.1016/j.bbagen.2012.03.012

9. Yen PM, Ando S, Feng X, Liu Y, Maruvada P, Xia X. Thyroid hormone action at the cellular, genomic and target gene levels. Mol Cell Endocrinol. (2006) 246:121-7. doi: 10.1016/j.mce.2005.11.030

10. Cheng SY. Thyroid hormone receptor mutations in cancer. Mol Cell Endocrinol. (2003) 213:23-30. doi: 10.1016/j.mce.2003.10.051

11. Laudet V, Begue A, Henry-Duthoit C, Joubel A, Martin P, Stehelin D, et al. Genomic organization of the human thyroid hormone receptor $\alpha$ (cerbA-1) Gene. Nucleic Acids Res. (1991) 19:1105-12. doi: 10.1093/nar/19. 5.1105

12. Cheng SY, Leonard JL, Davis PJ. Molecular aspects of thyroid hormone actions. Endocr Rev. (2010) 31:139-70. doi: 10.1210/er.2009-0007

13. Moore JMR, Galicia SJ, McReynolds AC, Nguyen N-H, Scanlan TS, Kiplin Guy R. Quantitative proteomics of the thyroid hormone receptor-coregulator interactions. J Biol Chem. (2004) 279:27584-90. doi: 10.1074/jbc.M403453200

14. Mangelsdorf DJ, Thummel C, Beato M, Herrlich P, Schütz G, Umesono $\mathrm{K}$, et al. The nuclear receptor superfamily: the second decade. Cell (1995) 83:835-9. 
15. Glass CK, Rosenfeld MG. The coregulator exchange in transcriptional functions of nuclear receptors. Genes Dev. (2000) 14:121-41. doi: 10.1101/gad.14.2.121

16. Lin JZ, Sieglaff DH, Yuan C, Su J, Arumanayagam AS, Firouzbakht S, et al. Gene specific actions of thyroid hormone receptor subtypes. PLoS ONE (2013) 8:e52407. doi: 10.1371/journal.pone.0052407

17. Cao X, Kambe F, Moeller LC, Refetoff S, Seo H. Thyroid hormone induces rapid activation of Akt/protein kinase B-mammalian target of rapamycinp70S6K cascade through phosphatidylinositol 3-kinase in human fibroblasts. Mol Endocrinol. (2005) 19:102-12. doi: 10.1210/me.2004-0093

18. Hiroi Y, Kim HH, Ying H, Furuya F, Huang Z, Simoncini T, et al. Rapid nongenomic actions of thyroid hormone. Proc Natl Acad Sci USA. (2006) 103:14104-9. doi: 10.1073/pnas.0601600103

19. Davis PJ, Leonard JL, Davis FB. Mechanisms of nongenomic actions of thyroid hormone. Front Neuroendocrinol. (2008) 29:211-8. doi: 10.1016/j.yfrne.2007.09.003

20. Hashizume K, Miyamoto T, Ichikawa K, Yamauchi K, Sakurai A, Ohtsuka $\mathrm{H}$, et al. Evidence for the presence of two active forms of cytosolic 3,5,3'Triiodo-L-Thyronine (T3)-binding protein (CTBP) in Rat kidney. Specialized functions of Two CTBPs in intracellular T3 translocation. J Biol Chem. (1989) 264, 4864-4871.

21. Vié MP, Blanchet P, Samson M, Francon J, Blondeau JP. High Affinity thyroid hormone-binding protein in human kidney: kinetic characterization and identification by photoaffinity labeling. Endocrinology (1996) 137:4563-70. doi: 10.1210/endo.137.11.8895318

22. Hashizume K, Suzuki S, Ichikawa K, Takeda T. Purification of Cytosolic 3,5,3'Triiodo-L-thyronine(T3)-binding protein(CTBP) which regulates nuclear T3 translocation. Biochem Biophys Res Commun. (1991) 174:1084-9.

23. Parkison C, Ashizawa K, McPhie P, Lin K-H, Cheng S-Y. The monomer of pyruvate kinase, subtype M1, is both a kinase and a cytosolic thyroid hormone binding protein. Biochem Biophys Res Commun. (1991) 179:668-74. doi: 10.1016/0006-291x(91)91424-b

24. Horiuchi R, Yamauchi K, Hayashi H, Koya S, Takeuchi Y, Kato K, et al. Purification and characterization of $55-\mathrm{kDa}$ protein with 3,5,3'-triiodo-Lthyronine-binding activity and protein disulfide-isomerase activity from beef liver membrane. Eur J Biochem. FEBS (1989) 183:529-38.

25. Primm TP, Gilbert HF. Hormone binding by protein disulfide isomerase, a high capacity hormone reservoir of the endoplasmic reticulum. J Biol Chem. (2001) 276:281-6. doi: 10.1074/jbc.M007670200

26. Kozlov G, Määttänen P, Thomas DY, Gehring K. A structural overview of the PDI family of proteins. FEBS J. (2010) 277:3924-36. doi: 10.1111/j.1742-4658.2010.07793.x

27. Alanen HI, Salo KEH, Pekkala M, Siekkinen HM, Pirneskoski A, Ruddock LW. Defining the domain boundaries of the human protein disulfide isomerases. Antioxid Redox Signal. (2003) 5:367-74. doi: 10.1089/152308603768295096

28. Laurindo FRM, Pescatore LA, de Castro Fernandes D. Protein disulfide isomerase in redox cell signaling and homeostasis. Free Radic Biol Med. (2012) 52:1954-69. doi: 10.1016/j.freeradbiomed.2012.02.037

29. Cai H, Wang CC, Tsou CL. Chaperone-like activity of protein disulfide isomerase in the refolding of a protein with no disulfide bonds. J Biol Chem. (1994) 269:24550-2.

30. McLaughlin SH, Bulleid NJ. Thiol-independent interaction of protein disulphide isomerase with type $\mathrm{X}$ collagen during intra-cellular folding and assembly. Biochem J. (1998) 331 (Pt 3):793-800.

31. Moretti AIS, Pavanelli JC, Nolasco P, Leisegang MS, Tanaka LY, Fernandes CG, et al. Conserved gene microsynteny unveils functional interaction between protein disulfide isomerase and rho guanine-dissociation inhibitor families. Sci Rep. (2017) 7:17262. doi: 10.1038/s41598-017-16947-5

32. Schultz-Norton JR, McDonald WH, Yates JR, Nardulli AM. Protein disulfide isomerase serves as a molecular chaperone to maintain estrogen receptor alpha structure and function. Mol Endocrinol. (2006) 20:1982-95. doi: 10.1210/me.2006-0006

33. Okada K, Imaoka S, Hashimoto S, Hiroi T, Funae Y. Over-expression of protein disulfide isomerase reduces the release of growth hormone induced by bisphenol A and/or T3. Mol Cell Endocrinol. (2007) 278:44-51. doi: 10.1016/j.mce.2007.08.005
34. Hashimoto S, Imaoka S. Protein-disulfide isomerase regulates the thyroid hormone receptor-mediated gene expression via redox factor1 through thiol reduction-oxidation. J Biol Chem. (2013) 288:1706-16. doi: 10.1074/jbc.M112.365239

35. Nakahira M, Macedo JNA, Seraphim TV, Cavalcante N, Souza TACB, Damalio JCP, et al. A draft of the human septin interactome. PLoS ONE (2010) 5:e13799. doi: 10.1371/journal.pone.0013799

36. Figueira ACM, Dias SMG, Santos MAM, Apriletti JW, Baxter JD, Webb $\mathrm{P}$, et al. Human thyroid receptor forms tetramers in solution, which dissociate into dimers upon ligand binding. Cell Biochem Biophys. (2006) 44:453-62. doi: 10.1385/CBB:44:3:453

37. Figueira ACM, Lima LMTR, Lima LHF, Ranzani AT, dos Santos Mule G, Polikarpov I. Recognition by the thyroid hormone receptor of canonical DNA response elements. Biochemistry (2010) 49:893-904. doi: 10.1021/bi90 $1282 \mathrm{~s}$

38. Figueira ACM, Polikarpov I, Veprintsev D, Santos GM. Dissecting the relation between a nuclear receptor and GATA: binding affinity studies of thyroid hormone receptor and GATA2 on TSH $\beta$ promoter. PLoS ONE (2010) 5:e12628. doi: 10.1371/journal.pone.0012628

39. Fattori J, Campos JLO, Doratioto TR, Assis LM, Vitorino MT, Polikarpov I, et al. RXR agonist modulates TR: corepressor dissociation upon 9-cisRetinoic acid treatment. Mol Endocrinol. (2015) 29:258-73. doi: 10.1210/me.2014-1251

40. Nascimento AS, Dias SMG, Nunes FM, Aparício R, Ambrosio ALB, Bleicher $\mathrm{L}$, et al. Structural rearrangements in the thyroid hormone receptor hinge domain and their putative role in the receptor function. J Mol Biol. (2006) 360:586-98. doi: 10.1016/j.jmb.2006.05.008

41. Tian G, Xiang S, Noiva R, Lennarz WJ, Schindelin H. The crystal structure of yeast protein disulfide isomerase suggests cooperativity between its active sites. Cell (2006) 124:61-73. doi: 10.1016/j.cell.2005.10.044

42. Krieger E, Vriend G. YASARA view - molecular graphics for all devices - from smartphones to workstations. Bioinformatics (2014) 30:2981-2. doi: 10.1093/bioinformatics/btu426

43. Kozakov D, Hall DR, Xia B, Porter KA, Padhorny D, Yueh C, et al. The ClusPro web server for protein-protein docking. Nat Protoc. (2017) 12:255-78. doi: 10.1038/nprot.2016.169

44. Cohen RN, Wondisford FE, Hollenberg AN. Two separate NCoR (nuclear receptor corepressor) interaction domains mediate corepressor action on thyroid hormone response elements. Mol Endocrinol. (1998) 12:1567-81. doi: $10.1210 /$ mend.12.10.0188

45. Shimizu H, Astapova I, Ye F, Bilban M, Cohen RN, Hollenberg AN. NCoR1 and SMRT play unique roles in thyroid hormone action in vivo. Mol Cell Biol. (2015) 35:555-65. doi: 10.1128/MCB.01208-14

46. Nagaya T, Jameson JL. Thyroid hormone receptor dimerization is required for dominant negative inhibition by mutations that cause thyroid hormone resistance. J Biol Chem. (1993) 268:15766-71.

47. Lonard DM, O'Malley BW. "Chapter 4: Emerging roles of the ubiquitin proteasome system in nuclear hormone receptor signaling," in Progress in Molecular Biology and Translational Science. Amsterdam: Elsevier (2009) p. 117-35. doi: 10.1016/s1877-1173(09)87004-x

48. Li S-J, Hong X-G, Shi Y-Y, Li H, Wang C-C. Annular arrangement and collaborative actions of four domains of protein-disulfide isomerase: a small angle X-ray scattering study in solution. J Biol Chem. (2006) 281:6581-8. doi: 10.1074/jbc.M508422200

49. Paquette MA, Atlas E, Wade MG, Yauk CL. Thyroid hormone response element half-site organization and its effect on thyroid hormone mediated transcription. PLoS ONE (2014) 9:e101155. doi: 10.1371/journal.pone.0101155

50. Velasco LFR, Togashi M, Walfish PG, Pessanha RP, Moura FN, Barra $\mathrm{GB}$, et al. Thyroid hormone response element organization dictates the composition of active receptor. J Biol Chem. (2007) 282:12458-66. doi: 10.1074/jbc.M610700200

51. Santos GM, Fairall L, Schwabe JWR. Negative regulation by nuclear receptors: a plethora of mechanisms. Trends Endocrinol Metab. (2011) 22:87-93. doi: 10.1016/j.tem.2010.11.004

52. Lopez G, Schaufele F, Webb P, Holloway JM, Baxter JD, Kushner PJ. Positive and negative modulation of jun action by thyroid hormone receptor at a unique AP1 site. Mol Cell Biol. (1993) 13:3042-9. doi: 10.1128/mcb.13.5.3042 
53. Brückner A, Polge C, Lentze N, Auerbach D, Schlattner U. Yeast twohybrid, a powerful tool for systems biology. Int J Mol Sci. (2009) 10:2763-88. doi: 10.3390/ijms10062763

54. Xu S, Sankar S, Neamati N. Protein disulfide isomerase: a promising target for cancer therapy. Drug Discov Tdy (2014) 19:222-40. doi: 10.1016/j.drudis.2013.10.017

55. Fu X-M, Zhu BT. Human pancreas-specific protein disulfide isomerase homolog (PDIp) is an intracellular estrogen-binding protein that modulates estrogen levels and actions in target cells. J Steroid Biochem Mol Biol. (2009) 115:20-9. doi: 10.1016/j.jsbmb.2009.02.008

56. Wilkinson B, Xiao R, Gilbert HF. A structural disulfide of yeast protein-disulfide isomerase destabilizes the active site disulfide of the n-terminal thioredoxin domain. J Biol Chem. (2005) 280:11483-7. doi: 10.1074/jbc.M414203200

57. Turano C, Coppari S, Altieri F, Ferraro A. Proteins of the PDI family: unpredicted non-ER locations and functions. J Cell Physiol. (2002) 193:15463. doi: $10.1002 /$ jcp. 10172

58. Gerner C, Holzmann K, Meissner M, Gotzmann J, Grimm R, Sauermann G. Reassembling proteins and chaperones in human nuclear matrix protein fractions. J Cell Biochem. (1999) 74:145-51.

59. Wen L, Fu L, Shi Y-B. Histone methyltransferase Dot1L Is a coactivator for thyroid hormone receptor during xenopus development. FASEB J. (2017) 31:4821-31. doi: 10.1096/fj.201700131R

60. Guan W, Guyot R, Samarut J, Flamant F, Wong J, Gauthier KC. Methylcytosine dioxygenase TET3 interacts with thyroid hormone nuclear receptors and stabilizes their association to chromatin. Proc Natl Acad Sci U.S.A. (2017) 114:8229-34. doi: 10.1073/pnas.1702192114

61. Yuan C, Nguyen P, Baxter JD, Webb P. Distinct ligand-dependent and independent modes of thyroid hormone receptor (TR)/PGC-1 $\alpha$ interaction. $J$ Steroid Biochem Mol Biol. (2013) 133:58-65. doi: 10.1016/j.jsbmb.2012.09.001

62. Hirota K, Matsui M, Iwata S, Nishiyama A, Mori K, Yodoi J. AP1 transcriptional activity is regulated by a direct association between thioredoxin and Ref-1. Proc Natl Acad Sci U.S.A. (1997) 94:3633-8.

63. Ema M, Hirota K, Mimura J, Abe H, Yodoi J, Sogawa K, et al. Molecular mechanisms of transcription activation by HLF and HIFlalpha in response to hypoxia: their stabilization and redox signal-induced interaction with CBP/p300. EMBO J. (1999) 18:1905-14. doi: 10.1093/emboj/18.7.1905

Conflict of Interest Statement: The authors declare that the research was conducted in the absence of any commercial or financial relationships that could be construed as a potential conflict of interest.

Copyright (c) 2019 Campos, Doratioto, Videira, Ribeiro Filho, Batista, Fattori, Indolfo, Nakahira, Bajgelman, Cvoro, Laurindo, Webb and Figueira. This is an open-access article distributed under the terms of the Creative Commons Attribution License (CC BY). The use, distribution or reproduction in other forums is permitted, provided the original author(s) and the copyright owner(s) are credited and that the original publication in this journal is cited, in accordance with accepted academic practice. No use, distribution or reproduction is permitted which does not comply with these terms. 